\title{
Rare earth element and neodymium isotope tracing of sedimentary rock weathering
}

\author{
Bayon Germain 1, *, Lambert Thibault ${ }^{2}$, Vigier Nathalie ${ }^{3}$, De Deckker Patrick ${ }^{4}$, Freslon Nicolas 1, 5 , \\ Jang Kwangchul ${ }^{6}$, Larkin Christina S. ${ }^{7}$, Piotrowski Alexander M. ${ }^{7}$, Tachikawa Kazuyo ${ }^{8}$, \\ Thollon Maude ${ }^{1}$, Tipper Edward T. ${ }^{7}$
}

1 IFREMER, Marine Geosciences Unit, Brest, France

2 Institute of Earth Surface Dynamics, University of Lausanne, Switzerland

${ }^{3}$ Laboratoire Océanographique de Villefranche sur Mer (LOV, OOV), CNRS, UPMC University of Paris

VI, Villefranche-sur-Mer, France

${ }^{4}$ Research School of Earth Sciences, The Australian National University, Canberra, Australia

5 Université de Bourgogne, UMR CNRS 6282 Biogéosciences, Dijon, France

${ }^{6}$ Division of Polar Paleoenvironment, Korea Polar Research Institute, Incheon, South Korea

7 Department of Earth Sciences, University of Cambridge, UK

${ }^{8}$ Aix Marseille University, CNRS, IRD, INRAE, Collège de France, CEREGE, Aix-en-Provence, France

*Corresponding author : Germain Bayon, email address : gbayon@ifremer.fr

\begin{abstract}
:
Chemical weathering plays an important role in sequestering atmospheric $\mathrm{CO} 2$, but its potential influence on global climate over geological timescales remains debated. To some extent, this uncertainty arises from the difficulty in separating the respective contribution of sedimentary and crystalline silicate rocks to past weathering rates in the geological record; two types of rocks having presumably different impact on the long-term carbon cycle. In this study, we investigate the use of rare earth element (REE) and neodymium isotopes $(\varepsilon N d)$ in leached iron oxide fractions of river sediments for tracing the origin of weathered rocks on continents. A new index, called 'concavity index' $(\mathrm{Cl})$, is defined for measuring the degree of mid-REE enrichment in geological samples, which enables the determination of the source of iron oxides in sediments, such as seawater-derived Fe-oxyhydroxide phases, ancient marine Fe oxides derived from the erosion of sedimentary rocks, and recent secondary oxides formed in soils via alteration of crystalline silicate rocks or pyrite oxidation. Using this index, we demonstrate that the $\varepsilon N d$ difference between paired $\mathrm{Fe}$-oxide and detrital fractions in river sediments (defined here as $\Delta \varepsilon N d$ Feox-Det) directly reflects the relative contribution of sedimentary versus crystalline silicate rocks during weathering. While rivers draining old cratons and volcanic provinces display near-zero $\Delta \varepsilon N d$ Feox-Det values indicative of dominant silicate weathering $(0.5 \pm 1.1 ; n=30)$, multi-lithological catchments hosting sedimentary formations yield systematically higher values $(2.7 \pm 1.2 ; n=44)$, showing that sedimentary rock weathering can be traced by the occurrence of riverine Fe oxides having more radiogenic $\mathrm{Nd}$ isotope signatures compared to detrital fractions. This assumption is reinforced by the evidence that calculated $\Delta \varepsilon N d$ Feox-Det values agree well with previous estimates for carbonate and silicate weathering rates in large river basins.
\end{abstract}

Examining the influence of climate and tectonics on measured $\mathrm{Nd}$ isotopic compositions, we find that $\Delta \varepsilon N d$ Feox-Det is strongly dependent on temperature in lowlands, following an Arrhenius-like relationship 
that reflects enhanced alteration of silicate rocks and formation of secondary Fe oxides in warmer climates. In contrast, in high-elevation catchments, $\Delta \varepsilon N d$ Feox-Det defines striking correlation with maximum basin elevation, which we also interpret as reflecting the intensification of silicate weathering and associated Fe oxide formation as elevation decreases, due to the combined effects of thicker soils and warmer temperature.

Overall, our new findings are consistent with previous assertions that the alteration of sedimentary rocks prevails in high-elevation environments, while silicate weathering dominates in floodplains. This novel approach combining REE and Nd isotopes opens new perspectives for disentangling the weathering signals of sedimentary and crystalline silicate rocks in the geologic record, which could be used in future studies to reassess the causal relationships between mountain uplift, erosion and climate throughout Earth's history

\section{Highlights}

World survey of REE and Nd isotopes in riverine Fe-oxides and detrital sediments A new REE index (concavity index) is defined to determine the types of iron oxides. $\Delta \varepsilon N d$ Feox-Det as a new proxy for sedimentary versus crystalline rock weathering $\Delta \varepsilon_{\text {Nd Feox-Det }}$ correlates with temperature and maximum elevation in watersheds. Shift from silicate- to carbonate-weathering regime from lowlands to mountains

Keywords: World rivers, iron oxides, neodymium isotopes, Mid-REE enrichment, concavity index, silicate weathering, carbonate weathering, sulphide weathering 


\section{Introduction}

On the continents, rocks are dissolved through chemical weathering, a process that consumes substantial amounts of carbon dioxide and plays a major role in regulating Earth's climate through time (Walker et al., 1981; Berner et al., 1983; Kump et al., 2000). A contentious view is that mountain building events during Earth's history were followed by enhanced physical erosion and accelerated dissolution of crystalline silicate rocks, resulting in a net drawdown of atmospheric $\mathrm{CO}_{2}$ and global climate cooling (e.g. Raymo and Ruddiman, 1992; Li and Elderfield, 2013). A first difficulty with this hypothesis has been the relatively small size of the atmospheric $\mathrm{CO}_{2}$ reservoir, meaning that over millions of years, any significant increase in $\mathrm{CO}_{2}$ removal via silicate weathering would have led to an unrealistic near complete depletion of carbon in the atmosphere (Berner and Caldeira, 1997). Additionally, several studies have also argued for relatively invariant silicate weathering rates at times when erosion of mountains was intensifying, suggesting that the evolution of atmospheric $\mathrm{CO}_{2}$ in response to mountain uplift could reflect progressive changes in the susceptibility of crystalline rocks to weathering, rather than being simply proportional to 
silicate weathering fluxes on continents (Willenbring and von Blanckenburg, 2010; Caves et al., 2016; Caves Rugenstein et al., 2019).

When examining the nature of the relationships between mountain uplift, chemical weathering and global climate, much complexity is brought by the fact that regions of high elevation are frequently composed of continental margin sequences of old sediments rather than crystalline basement (e.g. Hartmann and Moosdorf, 2012). These sequences invariably contain marine carbonates and other marine authigenic phases, which weather more rapidly than crystalline rocks. While mountainous regions with high denudation rates display the highest silicate weathering rates on continents (e.g. West et al., 2005), field observations indicate that chemical weathering fluxes from tectonically active mountain ranges are mostly dominated by dissolved inputs from carbonate weathering, even in watersheds hosting primarily igneous or metamorphic rocks (e.g. Stallard and Edmond, 1983; Jacobson and Blum, 2003; Jacobson et al., 2003; Moore et al., 2013). Carbonate weathering is generally considered to have no impact on the long-term carbon cycle. This is because the amount of carbon initially consumed during the dissolution of carbonate minerals by carbonic acid is quantitatively returned to the atmosphere upon subsequent carbonate precipitation in the ocean. However, carbonate dissolution on continents can also proceed in presence of sulphuric acid released by the oxidation of pyrite and other sulphide minerals (e.g. Spence and Telmer, 2005; Calmels et al., 2007; Torres et al., 2016; Torres et al., 2017). This coupled sulphide-carbonate weathering process can be particularly active in catchments hosting shales and other sulphide-bearing sedimentary formations, resulting, in terms of global impact on the carbon cycle, in a net release of $\mathrm{CO}_{2}$ to the atmosphere (e.g. Stallard and Edmond, 1983; Calmels et al., 2007; Torres et al., 2016; Blattmann et al., 2019). Similarly, the oxidation of petrogenic organic carbon stored in sedimentary rocks also returns $\mathrm{CO}_{2}$ to the atmosphere 
(Bouchez et al., 2010), especially in high mountains and glacial environments (Torres et al., 2016; Horan et al., 2017). On top of the current debate about the presumed importance of silicate weathering to the long-term carbon cycle, the above-mentioned evidence that alteration of carbonates and other sedimentary rocks dominate in high mountain environments have re-emphasized the need to characterize the separate evolution of sedimentary and crystalline silicate rock weathering through geologic time. To date, however, there is no reliable proxy that can decipher different rock weathering signatures from the geological record.

Continental detrital sediments may contain various authigenic mineral phases depending on the original source rock, including iron (Fe) oxides. Authigenic Fe oxide phases precipitate from water and pore fluids in the oceans, lakes and river estuaries, concentrating trace elements such as neodymium and beryllium (e.g. Boyle et al., 1977), which can be used to help identify the origin of weathered rocks on continents (e.g. von Blanckenburg et al., 2015; Hindshaw et al., 2018; Süfke et al., 2019; Jang et al., 2020). Iron oxides are also ubiquitous weathering products in soils, which can be transported as particulates in rivers prior to deposition as sediments (Bayon et al., 2004; Kraft et al., 2013). Recently, a study conducted in the Svalbard archipelago showed that the Fe oxide fractions leached from fjord sediments surrounding glaciated catchments composed of sedimentary rocks typically displayed $\mathrm{Nd}$ isotope signatures $\left({ }^{143} \mathrm{Nd} /{ }^{144} \mathrm{Nd}\right.$; or $\varepsilon_{\mathrm{Nd}}$ in epsilon notation) more radiogenic than corresponding detrital fractions (Jang et al., 2020). In agreement, Hindshaw et al. (2018) reported similar differences in $\varepsilon_{\mathrm{Nd}}$ between both the easily dissolvable component of catchment rocks and their silicate residues, and dissolved and particulate riverine loads in Svalbard. These data were interpreted as reflecting the preferential dissolution of marine precipitates hosted by sedimentary rocks. In fact, the same suggestion had been already 
presented more than two decades ago (Goldstein and Jacobsen, 1987), in order to account for the observation that the $\mathrm{Nd}$ isotopic composition of filtered river waters was also more radiogenic than corresponding suspended sediment loads in certain rivers. In the above mentioned examples, the evidence that significant $\mathrm{Nd}$ isotope decoupling can occur in sedimentary watersheds due to preferential alteration of marine precipitates is consistent with the fact that the global $\mathrm{Nd}$ isotopic composition of seawater $\left(\varepsilon_{\mathrm{Nd}}-8.8\right.$; Lacan et al., 2012) is on average more radiogenic than the mean continental detrital input to the ocean $(-11.3 \pm 2.5$; Bayon et al., 2015). Sedimentary carbonate rocks dissolve indeed at a much faster rate than crystalline silicate rocks, and therefore largely control the chemistry of river waters worldwide and associated dissolved inputs to the ocean (Gaillardet et al., 1999; Jacobson et al., 2002).

In this study, we define a novel approach based on the combined use of rare earth elements (REE) and $\mathrm{Nd}$ isotopes in the $\mathrm{Fe}$ oxide fraction associated with river sediments. Our approach exploits a systematic difference in $\mathrm{Nd}$ isotopic ratios between the Fe oxide and silicate fractions of the sediment (defined here as $\Delta \varepsilon_{\mathrm{Nd}}$ Feox-Det), similar to that observed between filtered waters and suspended particulate matter (Goldstein and Jacobsen, 1987; Hindshaw et al., 2018). This traces the relative contribution of sedimentary rock inputs with an inherited old authigenic $\mathrm{Nd}$ isotopic signature versus silicate rock inputs with a composition set by their silicate source. Our data set has a global reach, spanning samples from different lithologies, topographies and weathering regimes. The relative amounts of sedimentary- versus crystalline silicate- derived sources remaining in the riverine Fe oxide fraction are found to display systematic trends with basin parameters, such as temperature and relief that we link to different regimes of weathering, with fundamental implications for the silicate weathering feedback. 


\section{Materials and methods}

\subsection{World river sediments: Climatic, physical and lithological characteristics of watersheds}

We analysed a total of 74 sediment samples from either rivers $(n=43)$, deltas $(n=7)$, estuaries (tide-dominated environments; $\mathrm{n}=15$ ), or submarine deltas (wave-dominated environments; $\mathrm{n}=4$ ). Additionally, five marine sediment samples (Congo, Niger, Nile, Sepik, Gaoping) collected from more distal locations near the mouth of rivers, in deep-sea fan environments (Fig 1; Table S1). The geographical coordinates of studied samples are listed in Table S1. Selected samples include some of the world's largest rivers (e.g. Amazon, Congo, Mississippi, Nile, Yangtze, Mackenzie, Ganges-Brahmaputra), in addition to other smaller rivers associated with particular geological settings (Fig. 1). All river sediments were scooped from recent river banks or correspond to suspended particulates for the case of the Congo River tributaries. Other sediment samples were collected using various coring devices, corresponding typically to centimetre-thick layers of core-tops or sub-surface sediment horizons. All studied samples correspond either to modern or relatively recent sediments that have been presumably deposited during the last few centuries.

Mean annual air temperature (MAT) for each river system were derived from the literature (e.g. Pinet and Souriau, 1988; Bayon et al., 2016, 2018). Corresponding information for maximum elevation in river basins was either derived from Milliman and Farnsworth (2011), or determined in the geographical information system (GIS) software ArcGis (ESRI 2001, ArcGis Desktop 10.3.1) using the hydrological data and maps based on shuttle elevation derivatives HydroBASINS (Lehner and Grill, 2013). Finally, information on the lithological composition of each river basin was extracted from the GLiM global lithological map database (Table S1; Hartmann and Moosdorf, 2012). 
Studied samples were classified into distinct categories depending on the lithological composition of corresponding basins. A series of samples $(n=24)$ came from rivers draining igneous/metamorphic terranes, in particular from the Precambrian cratons of Africa (West African and Congo Shields), North America (Canadian Shield), northern South America (Guiana Shield), Fennoscandia, West Australia and Northwest Ireland. Six samples were derived from rivers draining both modern (New Zealand, Reunion Island, Indonesia) and ancient (Northern Ireland) volcanic provinces. The rest of studied samples $(n=44)$ corresponded to rivers draining mixed and/or sedimentary rock formations. This latter category of samples was sub-classified into 2 groups: rivers draining mountains (with maximum elevation $>1000 \mathrm{~m})$, including most of the world's largest rivers $(\mathrm{n}=30)$; and rivers draining lowlands, such as large Russian rivers (Volga, Don, Northern Dvina) and other small rivers from e.g. France and the British Isles $(n=14)$.

\subsection{Chemical preparation and sequential leaching procedure}

Sieved $(<63 \mu \mathrm{m})$ bulk sediment samples were first treated with $5 \%(\mathrm{v} / \mathrm{v})$ acetic acid (AA) for removal of carbonate minerals. Easily reducible Fe-oxide fractions were then extracted using a mixed solution of $15 \%(\mathrm{v} / \mathrm{v})$ AA and $0.05 \mathrm{M}$ hydroxylamine hydrochloride $(\mathrm{HH})$, following a procedure adapted from Bayon et al. (2002) and Gutjahr et al. (2007). With this latter leaching step, we specifically targeted the extraction of easily reducible and poorly crystalline Fe-oxide phases, such as ferrihydrite and lepidocrocite (Poulton and Canfield, 2005). The mineral fractions dissolved during this AA-HH leaching step are referred to as 'HH leachates' in the discussion below. Finally, after subsequent removal of organic compounds using 5\% hydrogen peroxide $\left(\mathrm{H}_{2} \mathrm{O}_{2}\right)$ solutions, silt-size $(\sim 4-63 \mu \mathrm{m})$ detrital fractions were separated from the residual detritus by centrifugation, prior to digestion by 
alkaline fusion (Bayon et al., 2015).

\subsection{Geochemical analyses}

Major (Mg, $\mathrm{Al}, \mathrm{Ca}, \mathrm{Mn}$ and $\mathrm{Fe}$ ) and trace element (REE, Y, Sr) concentrations in the $\mathrm{HH}$ leachates were determined with a Thermo Scientific Element XR sector field ICP-MS, using the Tm addition method (Barrat et al., 1996). Isobaric interferences on measured REE signals were corrected using oxide formation rates determined by analysing mono-elemental solutions of $\mathrm{Ba}-\mathrm{Ce}, \mathrm{Nd}-\mathrm{Pr}$ and $\mathrm{Sm}-\mathrm{Eu}-\mathrm{Gd}-\mathrm{Tb}$. The in-run uncertainties on all measurements were generally better than $5 \%$. The accuracy of our data was assessed by analysing seven different geological certified reference materials (AGV-1; AN-G; BCR-1; DR-N; UB-N; WSE; and IF-G, i.e. an iron-ore deposit). All results were in full agreement with reference values from the literature ( $<13 \%$; Table S2). Neodymium isotopic measurements were performed at the Pôle Spectrométrie Océan (Brest) using a Thermo Scientific Neptune multi-collector ICPMS, after Nd purification by conventional ion chromatography. Mass bias corrections on $\mathrm{Nd}$ were made with the exponential law, using ${ }^{146} \mathrm{Nd} /{ }^{144} \mathrm{Nd}=0.7219$, and ${ }^{143} \mathrm{Nd} /{ }^{144} \mathrm{Nd}$ corrected values were normalized to a JNdi-1 value of ${ }^{143} \mathrm{Nd} /{ }^{144} \mathrm{Nd}=0.512115$. Repeated analyses of a JNdi-1 standard solution during this study gave ${ }^{143} \mathrm{Nd} /{ }^{144} \mathrm{Nd}$ of $0.512121 \pm$ 0.000009 ( $2 \mathrm{SD}, \mathrm{n}=33$ ), hence corresponding to an external reproducibility of $\sim \pm 0.17 \varepsilon$ ( 2 SD). Epsilon Nd values $\left(\varepsilon_{\mathrm{Nd}}\right)$ were calculated using ${ }^{143} \mathrm{Nd} /{ }^{144} \mathrm{Nd}=0.512630$ (Bouvier et al., 2008).

\section{Results}

\subsection{Major and trace elements in the leachates}

For clarity, measured concentrations $(\mu \mathrm{g} / \mathrm{g})$ are reported relative to the initial mass of bulk $<63 \mu \mathrm{m}$ sample prior to leaching (Table S3). The HH leachates are dominated by Fe and Ca, 
except for two intensively weathered sediments from the Orinoco River Basin (i.e. Rio Caroni and Caura), both characterized by comparatively slightly higher Al abundances reflecting presumably the presence of gibbsite $\left(\mathrm{Al}(\mathrm{OH})_{3}\right)$ in these samples. Measured Fe/Ca ratios vary largely amongst studied leachates, from about 0.04 to $20(\mu \mathrm{g} / \mu \mathrm{g})$ (mean value of $\sim 3$ ). Note that three sediment samples (Nile, Danube, Var) display even lower Fe/Ca ratios $(<0.02)$ together with very high $\mathrm{Ca}$ concentrations (up to $20 \mathrm{wt} \%$ of initial sample mass), which indicate that they are largely dominated by carbonate material. Measured Fe/Mn ratios range from $\sim 1$ to 230 (mean value of $\sim 25$ ), mostly reflecting the predominance of Fe- over Mnoxide phases in most samples. Rare earth elements in sediment leachates also display a large range of concentrations (with $\mathrm{Nd}$ varying from $\sim 0.2$ to $28 \mu \mathrm{g} / \mathrm{g}$; mean $\sim 2.5 \mu \mathrm{g} / \mathrm{g}$; Table S3) and distribution patterns (Fig. 2), as normalized to the world river average silt values (WRAS; Bayon et al., 2015). The average REE patterns for each river category differ significantly from one group to another (Fig. 2). Note that shale-normalized REE patterns are also reported as normalized to Gd in Fig. 2, using the WRAS value for Gd $(5.188 \mu \mathrm{g} / \mathrm{g})$, in order to remove any dilution effect. The $\mathrm{HH}$ leachates from catchments dominated by igneous/metamorphic rocks are relatively enriched in light- (LREE) relative to heavy-REE (HREE) (Fig. 2a), while those from volcanic regions are characterized by marked LREE depletion (Fig 2b), both displaying shale-normalized patterns that closely resemble those for corresponding detrital clays (see Fig. 3 of Bayon et al., 2015). In contrast, the sediment leachates from multilithological catchments hosting sedimentary rocks are characterized by more pronounced midREE (MREE) enrichments relative to LREE and HREE (Fig. 2c,d).

\subsection{Neodymium isotopes}

Measured $\mathrm{Nd}$ isotopic compositions for the $\mathrm{HH}$ leachates are given in Table 1, together with $\varepsilon_{\mathrm{Nd}}$ values for corresponding detrital silt-size fractions. Note that a total of 49 data for 
silt-size fractions were already reported in Bayon et al. (2015). Detrital and Fe-oxide fractions from studied river sediments encompass a large range of $\varepsilon_{\mathrm{Nd}}$ values from -28.7/-30.9 (Churchill) to $+4.1 /+4.4$ (Brantas), respectively (Table 1; Fig. 3a). The $\mathrm{Nd}$ isotopic composition of Fe-oxide phases is almost systematically more radiogenic than associated detrital sediments, hence resulting in positive $\Delta \varepsilon_{\mathrm{Nd}}$ Feox-Det values, except for 7 samples (i.e. Kasai, Niger, Orinoco, Churchill, Kymijoki, Ume, Swilly) all derived from rivers draining old crystalline basement. River sediments from these ancient igneous/metamorphic provinces and volcanic regions display $\Delta \varepsilon_{\mathrm{Nd}}$ Feox-Det close to 0 epsilon units $(0.5 \pm 1.1 ; n=30$; Fig. $3 \mathrm{~b})$. In contrast, for the majority of samples where the basin lithology contains sedimentary rocks, the $\mathrm{Nd}$ isotopic composition $\left(\varepsilon_{\mathrm{Nd}}\right)$ of Fe oxide phases is systematically more radiogenic than associated silicate residues, resulting in positive $\Delta \varepsilon_{\mathrm{Nd}}$ Feox-Det in both lowlands $(2.1 \pm 0.3$; $\mathrm{n}=14)$ and mountainous $(2.4 \pm 0.7 ; \mathrm{n}=30)$ catchments. The observed differences in $\Delta \varepsilon_{\mathrm{Nd}}$ Feox-Det values are substantial and significant in magnitude; up to 6 epsilon units.

\section{Discussion}

\subsection{Significance of Nd isotope and REE compositions in leached sediment fractions}

\subsubsection{Identification of leached mineral phases}

An important prerequisite for interpreting measured REE and $\mathrm{Nd}$ isotopic compositions as potential weathering signatures in riverine Fe-oxides is to identify the different mineral phases dissolved during the chemical leaching. As mentioned above, the presence of relatively high $\mathrm{Ca}$ contents in the $\mathrm{HH}$ leachates indicates that substantial dissolution of residual carbonates (i.e. left behind the first AA extraction step) may have occurred. Using an endmember mixing model based on $\mathrm{Sr} / \mathrm{Ca}$ and $\mathrm{Mg} / \mathrm{Ca}$ ratios (Bayon et al., 2007), the relative proportions of aragonite, low-Mg calcite, high-Mg carbonates and silicate detritus in leached sediment fractions can be quantitatively estimated (Fig. 4). Most samples from catchments hosting 
igneous/metamorphic and volcanic rocks plot on a diffuse mixing trend between the silicate and low-Mg calcite endmembers, indicating that the Ca budget in these leachates is mostly controlled by detrital inputs (> 80\%). In contrast, the $\mathrm{HH}$ leachates from multi-lithological catchments generally extends towards the field of high-Mg carbonates characterized by low $\mathrm{Sr} / \mathrm{Ca}$ ratios (e.g. high-Mg calcite, dolomite, siderite). In leached sediment fractions from the Ganges and the rivers draining the eastern Canadian shield (Nelson, Churchill), more than $60 \%$ of extracted Ca appear to be derived from dolomite (Fig. 4). By analogy, the presence of high-Mg carbonates and partial dissolution of the silicate detritus could also account for some of the Fe signal in the HH leachates. However, except for a few samples (e.g. Nile, Danube, Mekong, Nelson, Churchill), most leachates display $\mathrm{Fe} / \mathrm{Mg}$ and $\mathrm{Fe} / \mathrm{Al}$ ratios that fall into the general range of values for various iron oxide formations and marine ferromanganese deposits, departing significantly from the high-Mg carbonate and silicate detritus endmember compositions (Fig. 5). This demonstrates that a substantial Fe fraction in the HH leachates is derived from the dissolution of Fe oxide phases. Importantly, the REE exhibit strong linear relationships with $\mathrm{Fe}$ in sediment leachates (e.g. $\mathrm{R}^{2}=0.84$ for $\mathrm{Gd}$ ), but no correlation with $\mathrm{Mg}$ or $\mathrm{Al}\left(\mathrm{R}^{2} \sim 0\right.$; graphs not shown). Therefore, although the chemical leaching may have resulted in the dissolution of detrital and carbonate phases, the above relationships between major elements implicitly suggest that the REE signal extracted with our HH solution is mostly associated with Fe-oxide phases.

\subsubsection{Potential issues related to the influence of particle-seawater interactions}

The fundamental premise behind the use of REE and $\mathrm{Nd}$ isotopes in both the silicate residue and $\mathrm{Fe}$ oxides is that they are tracers of source. Whilst the $\varepsilon_{\mathrm{Nd}}$ value and REE distribution patterns of the silicate residue can be relatively unambiguously interpreted as being controlled primarily by the provenance of the silicate material, REE and $\varepsilon_{\mathrm{Nd}}$ signatures 
of the Fe-oxide fractions of river sediments may be inherited from multiple sources and hence be more complicated to interpret. One particular concern is the fact that a number of samples in this study $(n=24)$ were collected in the marine environment (i.e. estuaries, submarine deltas, deep-sea fans), raising the possibility that their REE and Nd isotopic compositions partially reflect the influence of particle-seawater interactions and/or the presence of marine Fe-oxyhydroxide phases. In estuaries, while intense REE scavenging typically takes place in the low salinity regions, due to Fe-oxyhydroxide coprecipitation and coagulation of organic colloids, significant REE release can also occur when salinity increases, through dissolution of lithogenic suspended sediments (e.g. Sholkovitz et al., 2000; Rousseau et al., 2015). Taken together with other mechanisms, such as groundwater discharge and benthic fluxes (e.g. Johannesson and Burdige, 2007; Haley et al., 2017), these processes play an important role in controlling the oceanic distribution of REE and can certainly influence the REE distribution of labile sedimentary Fe-oxide phases at ocean margins, but also, to some extent, their $\mathrm{Nd}$ isotope composition (e.g. Adebayo et al., 2018). Despite this potential concern, several investigations have previously suggested that the sedimentary Fe-oxide fractions extracted from marine depositional settings receiving high inputs of river-borne material could still preserve a riverine $\varepsilon_{\mathrm{Nd}}$ signature (e.g. Bayon et al., 2004; Kraft et al., 2013; Jang et al., 2020). In this study, this latter hypothesis is supported by the fact that sedimentary Fe-oxides at the Niger deep-sea fan and those extracted from riverbank sediments collected along the Niger mainstem, both display similar $\varepsilon_{\mathrm{Nd}}$ and $\Delta \varepsilon_{\mathrm{Nd}}$ Feox-Det values (Table 1). Additionally, we do not observe any particular relationships between the degree of $\mathrm{Nd}$ isotope decoupling between detrital and Fe-oxide fractions and the types of depositional environments, as inferred from the similar range of $\Delta \varepsilon_{\mathrm{Nd}}$ Feox-Det values displayed by samples from both terrestrial (rivers, deltas) and marine (estuaries, submarine deltas, deep-sea fans) environments (Fig. S1). Nevertheless, the $\varepsilon_{\mathrm{Nd} \text { Feox }}$ value of the Congo deep-sea fan sediment $(-15.6 \pm 0.1)$ appears to be 
slightly more radiogenic than those for the suspended particulate loads of the Kasai $(-15.8 \pm$ $0.1)$ and Oubangui $(-16.9 \pm 0.1)$ rivers; i.e. the two main sediment contributors to the Congo River. In this particular case, this small $\mathrm{Nd}$ isotope discrepancy could possibly arise from the occurrence of seasonal $\varepsilon_{\mathrm{Nd}}$ variability within the Congo watershed (Allègre et al., 1996; Bayon et al., 2019), complicating the comparison between $\varepsilon_{\mathrm{Nd}}$ signatures of suspended loads, which represent an instantaneous snapshot of the chemical composition of river particulates, and of fine-grained sediments deposited near the mouth of rivers, which integrate spatiallyintegrated source signatures over a much longer period of time. Another exception is the case of the Nile River, for which our leachate $\varepsilon_{\mathrm{Nd}}$ value $(-5.4 \pm 0.1)$ strongly differs from the available dissolved $\varepsilon_{\mathrm{Nd}}$ estimate (-1.5; Scrviner et al., 2004). As discussed in the above section 4.1.1, this sample is clearly contaminated by the presence of biogenic carbonate material and, as a consequence, it probably hosts a substantial proportion of seawater-derived $\mathrm{Nd}$ scavenged from overlying water masses having distinctive $\varepsilon_{\mathrm{Nd}}$ composition ( -6.5; Tachikawa et al., 2004).

Based on the above discussion, our working hypothesis in the sections below is that the observed differences in both the degree of $\mathrm{Nd}$ isotope decoupling between detrital and $\mathrm{Fe}$ oxide fractions and the REE distribution patterns in riverine $\mathrm{Fe}$ oxides can carry useful information on weathering patterns in watersheds. This excludes those samples that are clearly dominated by carbonate phases (i.e. Nile, Danube, Var, Nelson, Churchill; see section 4.1.1). Finally, note that any of the conclusions that will be yielded below regarding the parameters controlling $\Delta \varepsilon_{\mathrm{Nd}}$ Feox-Det and other REE indices would still be valid if only considering the 'terrestrial' samples (i.e. excluding those deposited in marine-influenced environments). 


\subsection{Tracing the sedimentary origin of river Fe-oxides with REE patterns}

In addition to seawater-derived Fe-oxyhydroxide phases, another potential source of Feoxides in river sediments includes secondary oxide phases formed in soils during weathering processes. This type of Fe oxides is expected to dominate in floodplains and other transportlimited regions characterized by thick soil sequences, low denudation rates and intense silicate weathering processes (e.g. West et al., 2005). Secondary Fe oxides may also form in response to the alteration of sulphide minerals; a reaction that can further promote sulphuric acidmediated rock weathering in river catchments (e.g. Spence and Telmer, 2005; Calmels et al., 2007; Blattmann et al., 2019). Finally, the alteration and/or erosion of sedimentary rocks containing ancient marine $\mathrm{Fe}$ oxides is likely to influence the $\mathrm{REE}$ and $\mathrm{Nd}$ isotopic compositions of leached oxide fractions in sediments issued from glaciated catchments (Jang et al., 2020), but also in high mountainous and weathering-limited environments with high denudation rates, where reduced soil cover should be accompanied with limited formation of recent secondary Fe-oxides. Such preformed oxides correspond to 'old' authigenic phases formed presumably diagenetically at the time of sediment deposition in marine basins, hence inheriting the $\varepsilon_{\mathrm{Nd}}$ of seawater from that basin at that point in time and acquiring the REE signature of corresponding reduced pore waters (e.g. Haley et al., 2017).

As reported above, the $\mathrm{HH}$ leachates extracted from sedimentary catchments and multilithological river systems typically display MREE-enriched shale-normalized REE patterns, while those issued from rivers draining crystalline silicate rocks exhibit REE signatures mostly inherited from corresponding source rocks (Fig. 2). This can be quantified using indices, such as MREE/MREE*, that are generally calculated on a linear scale (e.g. Haley et al., 2004; Martin et al., 2010; Tostavin et al., 2016). In this study, the shape of the REE patterns was quantified differently, assuming that the behaviour of REE is linear on a log- 
linear plot (Lawrence and Kamber, 2005), and using shale-normalized ( $\mathrm{N}$ ) Gd and the geometric means of $\mathrm{La}_{\mathrm{N}}$ and $\mathrm{Yb}_{\mathrm{N}}$ (as illustrated in Fig. 2). This new index, referred to as concavity index $(\mathrm{CI})$, is defined as follows:

$$
\mathrm{CI}=\mathrm{Gd}_{\mathrm{N}} /\left(\mathrm{La}_{\mathrm{N}}^{6} \times \mathrm{Yb}_{\mathrm{N}}^{7}\right)^{1 / 13}
$$

The concavity index can be visually represented in a $(\mathrm{Gd} / \mathrm{Yb})_{\mathrm{N}} \mathrm{vs}(\mathrm{La} / \mathrm{Gd})_{\mathrm{N}}$ plot using (Eq. 2), where $x$ represents theoretical values for CI (Fig. 6):

$$
(\mathrm{La} / \mathrm{Gd})_{\mathrm{N}}=\left[(\mathrm{Gd} / \mathrm{Yb})_{\mathrm{N}} \times 1 / x\right]^{7 / 6} / x
$$

A CI value of $\sim 1$ indicates a quasi-linear shale-normalized REE pattern, such as those displayed by most detrital fractions of river sediments in Fig. 6 (see the $\mathrm{CI}=1$ line), except for those sediments derived from volcanic provinces. In contrast, a concavity index > 1 corresponds to shale-normalized REE patterns displaying downward-concave shapes, increasing as the degree of MREE enrichment relative to the other REE increases. Compared to the commonly used HREE/LREE vs MREE/MREE* plot (e.g. Haley et al., 2004; Martin et al., 2010; Du et al., 2016), the concavity index - and its representation within the $(\mathrm{Gd} / \mathrm{Yb})_{\mathrm{N}} \mathrm{vs}$ $(\mathrm{La} / \mathrm{Gd})_{\mathrm{N}}$ plot - appears to be particularly well-suited for distinguishing the potential influence of seawater, pore water and detrital signals in authigenic mineral phases (Fig. 6). While seawater typically displays $(\mathrm{Gd} / \mathrm{Yb})_{\mathrm{N}}$ values $<1$, sub-seafloor pore waters define a vertical array in Fig. 6, with $(\mathrm{Gd} / \mathrm{Yb})_{\mathrm{N}}$ values up to $\sim 2.5$. This array corresponds to the observed range of pore water REE signatures encountered in both oxic and reduced environments, extending from seawater-like distribution patterns (with CI 1) to pronounced MREE enrichments (with CI up to 2.5), respectively (e.g. Haley et al., 2004; Abbott et al., 2015). 
Most hydrogenous Fe-Mn crusts, diagenetic nodules and Fe-oxyhydroxide phases extracted from marine sediments overlap well with the field defined by pore waters (Fig. 6b), hence indicating that this array is probably also representative of marine Fe oxide precipitates.

In comparison, $\mathrm{Fe}$ oxide fractions from river sediments draining crystalline silicate rocks generally depart from the field of pore waters and marine Fe oxide precipitates (Fig. 7a), with volcanogenic Fe oxide fractions being clustered in the bottom-left part of the $(\mathrm{Gd} / \mathrm{Yb})_{\mathrm{N}}$ vs. $(\mathrm{La} / \mathrm{Gd})_{\mathrm{N}}$ plot (mean CI value: $2.1 \pm 0.4$; Fig. $2 \mathrm{~b}$ ), and Fe oxides derived from igneous and metamorphic provinces displaying comparatively higher $(\mathrm{La} / \mathrm{Gd})_{\mathrm{N}}$ values and CI values ranging between $\sim 2$ and 1.2 (mean CI value: $1.6 \pm 0.3$; Fig. 2 a). Instead, many riverine Fe oxides from both lowland and mountainous catchments draining sedimentary rocks are located within the field of marine authigenic Fe oxides (Fig. 7a), typically exhibiting CI values $>2$ (mean $\mathrm{CI}$ values of $2.3 \pm 0.3$ and $2.4 \pm 0.7$, respectively; Fig. $2 \mathrm{c}, \mathrm{d})$. Based on the above discussion, this observation suggests that such MREE enrichments in riverine Fe oxide fractions probably trace the source signature of ancient marine Fe oxides associated with the erosion and/or alteration (followed by subsequent precipitation of Fe-oxyhydroxides in soils or river systems) of sedimentary rocks. Upon formation, sedimentary rocks are likely to experience various diagenetic and post-depositional processes, which most probably result in the preferential dissolution of easily dissolvable hydrogenous Fe oxyhydroxide phases and possibly explaining why riverine oxides derived from multi-lithological catchments plot in the upper part of the field defined by pore waters (Fig. 7a). An exception is the case of those $\mathrm{HH}$ leachates extracted from the Rhine, Var and Nile sediment samples, which display markedly lower CI values ( 1.6). However, as discussed above, these HH leachates are dominated by biogenic carbonates and presumably also contain a fraction of marine hydrogenous $\mathrm{Fe}$ oxyhydroxides, which could hence explain their particular REE distribution patterns. 
Interestingly, in Fig. 7a, a number of samples from multi-lithological catchments depart from the fields for pore waters and marine Fe-oxyhydroxide phases. This includes the samples from the Narva and Vistula rivers, which both drain extensive sedimentary rock formations from the East European platform (Table S1) that could be possibly tagged with distinctive REE signatures, but also the samples from the Ganges-Brahmaputra river system and the Lower River Bann in Northern Ireland, which plot in the field of volcanogenic Fe-oxides (Fig. 7a). A large part of the Lower River Bann catchment is composed of Tertiary basalts (34\%; Table S1), meaning that partial dissolution of volcanogenic Fe-oxide and/or detrital particles is likely to have occurred in this particular sample during the HH leaching step. In contrast, the Ganges-Brahmaputra river basin only host minor amounts of volcanic rocks $(\sim 6 \%)$, hence making a contamination by volcanogenic particles unlikely in these samples. Instead, we speculate that the distinctive REE signatures observed in these leachates could point towards a particular source composition, perhaps related to the presence of extensive metamorphosed carbonate deposits within the G.-B. watershed (e.g. Jacobson et al., 2002; Bickle et al., 2005). This latter hypothesis would be in agreement with the presumed evidence for the presence of dolomite in the same HH leachates, as inferred from major element data (see section 4.1.1).

Another striking feature of our results is the fact that a few Fe oxide fractions display REE concavity indices distinctively higher than previously investigated marine $\mathrm{Fe}-\mathrm{Mn}$ oxyhydroxide phases and reduced pore waters (Fig. 7a). This corresponds in particular to the following samples: Fly (CI = 4.5), Mackenzie (4.1), Gaoping (3.5) and Paraná (3.2) rivers (Fig. 7a). For these latter samples, we do not have any clear explanation for the occurrence of such pronounced MREE enrichments. One hypothesis would be that these REE characteristics relate to the oxidation of sulphide minerals in corresponding watersheds. Previous investigations have indeed shown that intense sulphide weathering proceeds in at least two of 
these river catchments (i.e. Mackenzie and Gaoping), strongly influencing the chemistry of their dissolved river loads (Calmels et al., 2007; Blattmann et al., 2019). The oxidative weathering of pyrite and other sulphide minerals commonly leads to the formation of secondary $\mathrm{Fe}$ oxides, but can also result in siderite $\left(\mathrm{FeCO}_{3}\right)$ precipitation in environments dominated by carbonate weathering (e.g. Lara et al., 2015). Siderite is also a common diagenetic mineral in marine sediments and shales, typically characterized by strong depletion of LREE (e.g. Bau and Möller, 1992; Franchi et al., 2017) and pronounced MREE enrichments (with CI up to 50; Rongemaille et al., 2011). In the $\mathrm{Sr} / \mathrm{Ca} v \mathrm{Mg} / \mathrm{Ca}$ plot (Fig. 4), the above mentioned rivers (i.e. Fly, Mackenzie, Gaoping and Paraná) do not appear to cluster in the immediate proximity of the siderite endmember, hence suggesting that the occurrence of high CI values in these particular samples may more directly reflect the presence of secondary Fe oxides derived from sulphide-oxidation processes. While further investigation would be clearly needed to more precisely identify the various mechanisms controlling the distribution of REE in river Fe oxide fractions, the main message from the above discussion is that the shape of shale-normalized REE patterns and corresponding concavity index can be used to identify the source of leached Fe oxide phases in sediments: i.e. marine Fe-Mn oxyhydroxide phases, volcanogenic Fe oxides, secondary Fe oxides related to the alteration of silicate rocks, secondary Fe oxides (or other mineral phases) related to the oxidation of sedimentary sulphide minerals, and ancient marine oxides associated with sedimentary rocks (Fig. 7a). Importantly, a remarkable feature of our results is that the occurrence of pronounced MREE enrichments (with CI > 2) represents an ubiquitous characteristics of riverine Fe oxides derived from sedimentary catchments.

\subsection{Causes of non zero $\Delta \varepsilon_{\mathrm{Nd}}$ Feox-Det}

For samples draining crystalline rocks (granitic, metamorphic and basaltic rocks), the Fe- 
oxide fraction has a $\varepsilon_{\mathrm{Nd}}$ that is similar to the silicate residue (Fig. 3). This indicates that these Fe-oxides have sourced their $\mathrm{Nd}$, and by inference Fe, from silicate weathering of the source rocks. Except maybe for the Churchill River sample, which was shown to contain substantial amounts of sedimentary dolomite (see section 4.1), the observed $\Delta \varepsilon_{\mathrm{Nd}}$ Feox-Det variability in all other rivers draining crystalline silicate basement most likely reflect subtle $\mathrm{Nd}$ isotopic decoupling during incongruent silicate weathering (e.g. Dausmann et al., 2019). In contrast, in sedimentary and multi-lithological catchments, the appreciable and systematic difference in $\varepsilon_{\mathrm{Nd}}$ between the Fe oxide fraction and silicate residue demonstrates that the REE and Fe in the oxides must have a distinct origin from the silicate detrital material. This observation is supported by the evidence that $\Delta \varepsilon_{\mathrm{Nd}}$ Feox-Det display a broad correlation with the concavity index in leached sediment fractions (Fig. 7b). Based on the above discussion (section 4.2), this general relationship indicates that the degree of $\mathrm{Nd}$ isotope decoupling between paired Fe-oxide and detrital fractions in river sediments is mostly controlled by the relative contribution of secondary Fe oxides derived from the alteration of crystalline silicate rocks (typically characterized by $\Delta \varepsilon_{\mathrm{Nd} \text { Feox-Det }}<1.6$ and CI values $<2$ ) and ancient marine Fe oxides derived from the erosion and/or alteration of sedimentary rocks in watersheds (with $\Delta \varepsilon_{\mathrm{Nd}}$ FeoxDet > 1.6 and CI values > 2). Interestingly, the observed REE differences reported above between sedimentary watersheds possibly influenced by sulphide weathering (with $\mathrm{CI}>2.5$ ) and the other high-elevation catchments (with CI < 2.5) are not accompanied by any particular differences in $\Delta \varepsilon_{\mathrm{Nd}}$ Feox-Det values. This indicates that the difference in the $\mathrm{Nd}$ isotopic composition of paired Fe oxide and detrital fractions probably represents a more effective tracer than REE distribution patterns for identifying the respective contribution of sedimentary versus crystalline silicate rocks to weathering, whilst REE can provide additional complementary constraints on the type of Fe oxides and associated weathered rocks. 


\subsection{Links between $\Delta \varepsilon_{N d}$ Feox-Det and carbonate weathering indices based on river chemistry}

In order to further investigate whether riverine Fe-oxide phases can be used for tracing the origin of weathered rocks in watersheds, we can also compare our $\Delta \varepsilon_{\mathrm{Nd}}$ Feox-Det values to previous estimates of carbonate and silicate weathering rates in large river basins, as inferred from inverse modelling of river chemistry data (Gaillardet et al., 1999). Apart from a few particular exceptions, most rivers display a general correlation between $\Delta \varepsilon_{\mathrm{Nd}}$ Feox-Det and the relative contribution of carbonate versus silicate rock weathering in corresponding watersheds (Fig. 8). Amongst the rivers that depart significantly from these relationships, the Yangtze, Seine and Rhine rivers correspond to highly industrialized and polluted river systems. As previously suggested for the Seine River using Fe isotopes, it is possible that a fraction of Feoxides hosted in these samples derives from anthropogenic activities (Chen et al., 2014). Following the discussion in section 4.2, another potential contamination issue comes from the preferential alteration of easily dissolvable volcanic rocks in watersheds (and also potentially during the leaching process; Elmore et al., 2011), presumably accompanied by highly radiogenic signatures. This effect could possibly account for the high $\Delta \varepsilon_{\mathrm{Nd}}$ Feox-Det values determined in the leached sediment fractions from the Paraná and Fraser river basins, which both depart from the observed relationships in Fig. 8. Although the influence of any contamination by volcanogenic material in these particular samples was not suspected from REE data (i.e. these two samples plotting away from the volcanogenic Fe oxide endmember in Fig. 6), both catchments do indeed cover extensive areas of flood basalts and other volcanic formations ( 14\% and 40\%, respectively; Table S1), so that it is possible that their $\mathrm{Nd}$ isotopic composition and corresponding $\Delta \varepsilon_{\mathrm{Nd}}$ Feox-Det signatures are biased towards more radiogenic composition. Taken together with the findings from sections 4.2 and 4.3 , the general agreement observed between $\Delta \varepsilon_{\mathrm{Nd}}$ Feox-Det and rock weathering indices inferred from 
river chemistry data provides additional evidence that leached Fe-oxide fractions from riverborne sediments can be used to characterize the relative contribution of sedimentary versus crystalline silicate rock weathering in watersheds.

\subsection{Temperature-dependency of $\Delta \varepsilon_{\mathrm{Nd} \text { Feox-Det }}$ in lowlands}

There is plentiful evidence for the dependence of mineral dissolution rates on climate and tectonics (e.g. Velbel, 1993; White et al., 1999; West et al., 2005; West, 2012; Gaillardet et al., 2019). As a consequence, the climatic and geomorphic characteristics of studied catchments can also be used to provide information on the factors controlling the distribution of $\mathrm{Nd}$ isotopes in riverine $\mathrm{Fe}$ oxides, and to further investigate their potential utility as weathering proxies. Below, we examine the relationships between $\Delta \varepsilon_{\mathrm{Nd}}$ Feox-Det and: i) the mean annual temperature (MAT); ii) the maximum basin elevation; and iii) the percentage area of carbonaceous sedimentary rocks in studied catchments, which, to a first approximation, can be used as proxies for the climate, geomorphic and lithological parameters in catchments. In rivers draining lowlands, measured $\varepsilon_{\mathrm{Nd}}$ differences between paired Fe-oxide and detrital sediment fractions define a strong exponential anti-correlation $\left(\mathrm{R}^{2}=0.62 ; \mathrm{n}=11\right.$; Fig. 9a) with temperature, but no particular relationships with maximum elevation (Fig. 9b) and lithology (Fig. 9c). An exponential dependency of $\Delta \varepsilon_{\mathrm{Nd}}$ Feox-Det on temperature is strongly suggestive of a relationship similar to the Arrhenius dependency of silicate mineral dissolution rates $(\varpi)$ of the form: $\varpi=\mathrm{A} \mathrm{e}^{-E a / R T}$, where $\mathrm{A}$ is a pre-exponential factor, $E_{\mathrm{a}}$ the activation energy and $R$ the gas constant. Silicate weathering rates increase exponentially with temperature as demonstrated in previous experimental and field-based investigations (White et al., 1999; Li et al., 2016). This visible Arrhenius dependency is what would be predicted for transport-limited weathering regimes, where the temperature dependency of silicate mineral dissolution occurs at a faster rate than the supply of detrital material through 
denudation and erosion. In low-elevation regions and other transport-limited weathering environments, the above relationship between $\Delta \varepsilon_{\mathrm{Nd}}$ Feox-Det and MAT hence probably reflects the combination of two factors: 1) the increased rate of secondary Fe oxide formation as both temperature and silicate weathering intensity increases; and 2) the dissolution of carbonaceous rocks and associated ancient marine Fe oxides, which occur preferentially between 10 and $15^{\circ} \mathrm{C}$ in river catchments (Gaillardet et al., 2019).

\subsection{Elevation-dependency of $\Delta \varepsilon_{\mathrm{Nd} \text { Feox-Det }}$ in mountainous catchments}

For mixed lithology mountainous basins, measured $\Delta \varepsilon_{\mathrm{Nd}}$ Feox-Det values do not display any correlation with temperature (Fig. 10a), but define instead a striking positive relationship with maximum basin elevation $\left(R^{2}=0.75 ; n=21\right.$; Fig. $\left.10 b\right)$, where the catchments with the highest elevations display the most positive $\Delta \varepsilon_{\mathrm{Nd}}$ Feox-Det values. Note that those samples potentially influenced by: i) anthropogenic contamination (Yangtze, Rhine; see section 4.4); ii) the dissolution of silicate detritus (Mekong; Fig. 5); iii) the dissolution of volcanogenic material in catchments draining large areas of volcanic rocks (Fraser: 40\%; Chubut: 31\%; Sefid Rud: 29\%; Paraná: 14\%; Table S1); or iiii) the presence of high amounts of carbonates in corresponding leachates (Nile, Danube, Nelson; section 4.1.1), were excluded from the regression analysis.

One hypothesis is that the observed relationship between $\Delta \varepsilon_{\mathrm{Nd}}$ Feox-Det and maximum elevation in corresponding watersheds simply reflects the overabundance of sedimentary rocks in mountainous regions relative to crystalline silicate rocks. Assuming that limestones and dolostones preferentially outcrop in high-elevation regions rather than in lowlands, it would make sense that the proportion of ancient marine Fe oxides in river sediments increases as elevation increases in watersheds. However, neither $\Delta \varepsilon_{\mathrm{Nd}}$ Feox-Det (Fig. 10c), maximum 
elevation (Fig. S2a), nor carbonate weathering indices (Fig. S2b) appear to correlate with the percentage areal coverage of carbonaceous sedimentary rocks in studied watersheds, hence making this assumption unlikely. This apparent lack of lithological control on $\Delta \varepsilon_{\text {Nd Feox-Det }}$ and other weathering indices in studied watersheds is coherent with the fact that mineral dissolution rates in high-mountain environments are primarily controlled by climate and geomorphic parameters (Riebe et al., 2001; Jacobson et al., 2003; West et al., 2005; West, 2012). To some extent, it could also indicate that a substantial proportion of carbonate weathering in high-elevation watersheds is not derived from carbonaceous sedimentary rocks, but from various trace carbonate phases associated for example with siliciclastic sediments (e.g. Hartmann et al., 2014).

Instead, we hypothesise that in mountainous catchments the observed difference in $\varepsilon_{\mathrm{Nd}}$ is large when a significant fraction of the ancient marine Fe-oxides remains in the sediment, but becomes gradually reduced as the degree of weathering of the detrital fraction increases, when 'young' secondary oxides derived from modern silicate weathering progressively replace or overprint the ancient marine $\mathrm{Nd}$ signal preserved in riverine Fe oxide fractions. Areas of high topography typically have high denudation rates and are commonly weathering-limited as defined by water chemistry (e.g. West et al., 2005; West et al., 2012). This means that the rate of supply of particulate material in these high-elevation environments is more rapid than silicate mineral dissolution. Because the rate of silicate mineral dissolution is low relative to the supply of particulate matter, there is little scope to reset the $\varepsilon_{\mathrm{Nd}}$ of Fe oxides through recrystallization and addition of $\mathrm{Nd}$ through silicate mineral dissolution. As elevation decreases, denudation rates also decrease, making the proportion of silicate mineral dissolution higher relative the supply of particulate matter. In this case, the $\varepsilon_{\mathrm{Nd}}$ of Fe-oxides becomes progressively reset by supply of $\mathrm{Nd}$ from silicate dissolution and, as a consequence, 
$\Delta \varepsilon_{\mathrm{Nd}}$ Feox-Det decreases. This hypothesis would be in full agreement with results obtained earlier for various river basins in Switzerland and New Zealand, which have clearly shown that silicate weathering rates significantly decrease with increasing elevation (Drever and Zobrist, 1992; Jacobson and Blum, 2003; Jacobson et al., 2003; Moore et al., 2013).

Given the temperature dependency that is observed in lowlands, it is possible that the observed relationship between maximum basin elevation and $\Delta \varepsilon_{\mathrm{Nd}}$ Feox-Det in mountainous regions (Fig. 10b) could be partially driven by temperature in upstream catchment areas (i.e. differing from the mean annual temperatures listed in Table 1, which correspond to the mean average $\mathrm{T}^{\circ} \mathrm{C}$ at the entire basin scale). It is well known that temperature decreases with elevation in mountains. Although this relationship may vary significantly, as a function of moisture for example, the corresponding temperature gradient (i.e. the so-called adiabatic thermal lapse rate) is generally about $0.6^{\circ} \mathrm{C}$ per $100 \mathrm{~m}$ (Meyer, 1992). In lowlands, the observed range of temperature $\left(\sim 20^{\circ} \mathrm{C}\right)$ between sub-Arctic (e.g. Northern Dvina) and subtropical (Fitzroy) catchments corresponds to about $3 \Delta \varepsilon_{\text {Nd Feox-Det }}$ units (Fig. 9). To a first approximation, the same range of temperature would represent about a $3500 \mathrm{~m}$ difference in elevation in mountainous regions. Interestingly, this would be fully coherent with the observed evolution of $\Delta \varepsilon_{\mathrm{Nd}}$ Feox-Det with elevation in Fig. 10, ranging from $\sim 1$ to 4 between about $2000 \mathrm{~m}$ and $5500 \mathrm{~m}$. By analogy, this observation would suggest that temperature also plays a role in controlling the evolution of $\Delta \varepsilon_{\mathrm{Nd}}$ Feox-Det in mountainous regions, through direct effect on the relative contribution of sedimentary versus crystalline silicate rock to total weathering rates. In contrast to high-elevation catchments, where cold temperatures inhibit the dissolution of silicate minerals, the gradual shift towards warmer temperatures as elevation decreases would be accompanied by intensifying silicate weathering and, as a consequence, enhanced precipitation of secondary $\mathrm{Fe}$ oxides, resulting in turn in river 
sediments having lower $\Delta \varepsilon_{\text {Nd Feox-Det }}$.

\subsection{Final implications and future perspectives}

One important implication of our results is that high mountains and glacial environments are dominated by alteration of sedimentary rocks, whereas silicate weathering prevails in lowelevation environments. This finding is entirely consistent with previous works, which proposed a similar decoupled weathering pattern between 'cold' tectonically active high mountain ranges - where carbonates and other sedimentary rocks are preferentially weathered, and 'warm' floodplains - characterised by more intense silicate weathering (e.g. Stallard and Edmond, 1983; Jacobson and Blum, 2003; Jacobson et al., 2003; Moore et al., 2013; Torres et al., 2016; Yu et al., 2020). In contrast with the above-mentioned studies, mostly based on water chemistry data, our new approach that combines the use of REE and Nd isotopes in leached Fe oxide fractions of river-borne sediments could be potentially applicable to sediment records, thereby providing a novel means for reconstructing the evolution of sedimentary versus crystalline silicate weathering during past mountain building events, and its links to the global carbon cycle and climate. This would require a careful selection of well-suited sedimentary records located near the mouth of large river systems (e.g. Amazon margin, Bay of Bengal) and characterized by high sedimentation rates of terrigenous material. An important prerequisite for applying this new approach to sediment records will also be to investigate whether leached Fe oxide phases truly correspond to river-borne oxides and assess the extent to which early diagenesis and other post-depositional processes may affect the preservation of pristine $\mathrm{REE}$ and $\mathrm{Nd}$ isotope signatures.

\section{Concluding remarks}

This study reports on a novel approach for disentangling silicate and non-silicate weathering signals in the sedimentary record based on rare earth elements and neodymium isotopes. In modern river sediments, the $\mathrm{Nd}$ isotopic difference between paired iron oxide and 
detrital fractions $\left(\Delta \varepsilon_{\mathrm{Nd} \text { Feox-Det }}\right)$ can provide qualitative information on the relative contribution of sedimentary versus crystalline silicate rocks during continental weathering, in line with previous estimates based on river chemistry data. In order to better distinguish between $\mathrm{Fe}$ oxides derived from the erosion and/or alteration of sedimentary rocks in river catchments and secondary Fe oxides related to silicate weathering or oxidative weathering of sulphide minerals in soils, a new REE index is also proposed: the concavity index (CI), which provides a quantitative measure of the shape of shale-normalized patterns and corresponding MREE enrichments. Overall, our global survey for $\mathrm{Nd}$ isotopes and $\mathrm{REE}$ in river sediments demonstrates a clear link between $\Delta \varepsilon_{\mathrm{Nd}}$ Feox-Det, temperature and maximum elevation in river basins, which reflects a gradual temperature-dependent shift from silicate- to carbonatedominated weathering regimes, from lowlands to high-mountain environments, respectively.

\section{Acknowledgements}

We gratefully acknowledge all our friends and colleagues who very kindly provided us with the studied samples: O. Adeaga, J. Allard, C. Bigler, F. Busschers, G. Calvès, K. Cohen, F. Darchambeau, B. Dennielou, F.X. Gingele, S. Goodbread, D. Haynes, P.R. Hill, B. Hoogendoorn, S. Jorry, G. Kowaleska, T. Leipe, S. Leroy, L. Lopez, J.P. Lunkla, I. Mendes, D. Meunier, J.C. Montero-Serrano, C. Nittrouer, A. Pasquini, V. Ponomareva, D; Repert, G. Saint-Onge, E. Schefuß, V. Shevchenko, L. Tiron, S. VanLaningham, A. Wheeler; with special thanks to A. Borges, S. Toucanne, and Y. Saito. We are also grateful to A. De Prunelé and J.A. Barrat for assistance during MC-ICPMS analyses and fruitful discussions regarding REE distribution patterns, respectively. Finally, we thank the Editor (K. Johannesson) and the anonymous reviewers who provided very constructive and insightful comments on the earlier versions of this manuscript. This work was funded through an IEF Marie Curie fellowship to G.B. (SI-PALEO; Grant No. FP7-PEOPLE-2012-IEF 327778). ETT was funded by NERC Grant (NE/P011659/1) for research into sediment compositions of large rivers. 


\section{References}

Adebayo, S.B., Cui, M., Hong, T., Johannesson, K.H., Martin, E.E., 2018. Rare earth elements geochemistry and $\mathrm{Nd}$ isotopes in the Mississippi River and Gulf of Mexico mixing zone. Front. Mar. Sci. 5, 166.

Abbott, A.N., Haley, B.A., McManus, J., Reimers, C.E., 2015. The sedimentary flux of dissolved rare earth elements to the ocean. Geochim. Cosmochim. Acta 154, 186-200.

Allègre, C.J., Dupré, B., Négrel, P., Gaillardet, J., 1996. Sr-Nd-Pb isotope systematics in Amazon and Congo River systems: constraints about erosion processes. Chem. Geol. $131,93-112$.

Barrat, J.A., Keller, F., Amossé, J., Taylor, R.N., Nesbitt, R.W., Hirata, T., 1996. Determination of rare earth elements in sixteen silicate reference samples by ICP-MS after Tm addition and ion exchange separation. Geostand. Newslett. 20, 133-139.

Basak, C., Martin, E.E., Kamenov, G.D., 2011. Seawater Pb isotopes extracted from Cenozoic marine sediments. Chem. Geol. 286, 94-108.

Bau, M., Möller, P., 1992. Rare earth element fractionation in metamorphogenic hydrothermal calcite, magnesite and siderite. Min. Petrol. 45, 231-246.

Bayon, G., German, C.R., Boella, R.M., Milton, J.A., Taylor, R.N., Nesbitt, R.W., 2002. An improved method for extracting marine sediment fractions and its application to $\mathrm{Sr}$ and Nd isotopic analysis. Chem. Geol. 187, 179-199.

Bayon, G., German, C.R., Burton, K.W., Nesbitt, R.W., Rogers, N., 2004. Sedimentary FeMn oxyhydroxides as paleoceanographic archives and the role of aeolian flux in regulating oceanic dissolved REE. Earth Planet. Sci. Lett. 224, 477-492.

Bayon, G., Pierre, C., Etoubleau, J., Voisset, M., Cauquil, E., Marsset, T., Sultan, N., Le Drezen, E., Fouquet, Y., 2007. $\mathrm{Sr} / \mathrm{Ca}$ and $\mathrm{Mg} / \mathrm{Ca}$ ratios in Niger Delta sediments: implications for authigenic carbonate genesis in cold seep environments. Mar. Geol. 241, 
93-109.

Bayon, G., Burton, K.W., Soulet, G., Vigier, N., Dennielou, B., Etoubleau, J., Ponzevera, E., German, C.R., Nesbitt, R.W., 2009. Hf and Nd isotopes in marine sediments: Constraints on global silicate weathering. Earth Planet. Sci. Lett. 277, 318-326.

Bayon, G. et al., 2015. Rare earth elements and neodymium isotopes in world river sediments revisited. Geochim. Cosmochim. Acta 170, 17-38.

Bayon, G., Skonieczny, C., Delvigne, C., Toucanne, S., Bermell, S., Ponzevera, E., André, L., 2016. Environmental Hf-Nd isotopic decoupling in World river clays. Earth Planet. Sci. Lett. $438,25-36$.

Bayon, G., Delvigne, C., Ponzevera, E., Borges, A.V., Darchambeau, F., De Deckker, P., Lambert, T., Monin, L., Toucanne, S., André, L., 2018. The silicon isotopic composition of fine-grained river sediments and its relation to climate and lithology. Geochim. Cosmochim. Acta 229, 147-161.

Bayon, G, Schefuss, E., Dupont, L., Borges, A.V., Dennielou, B., Lambert, T., Mollenhauer, G., Monin, L., Ponzevera, E., Skonieczny, C., André, L., 2019. The roles of climate and human land-use in the late Holocene rainforest crisis of Central Africa. Earth Planet. Sci. Lett. 505, 30-41.

Berner, R.A., Lasaga, A.C., Garrels, R.M, 1983. The carbonate-silicate geochemical cycle and its effect on atmospheric carbon dioxide over the past 100 million years. Am. J. Sci. 283, 641-683.

Berner, R.A., Caldeira, K., 1997. The need for mass balance and feedback in the geochemical carbon cycle. Geology 25, 955-956.

Bickle, M.J., Chapman, H.J., Bunbury, J., Harris, N.B., Fairchild, I.J., Ahmad, T., Pomiès, C., 2005. Relative contributions of silicate and carbonate rocks to riverine $\mathrm{Sr}$ fluxes in the headwaters of the Ganges. Geochim. Cosmochim. Acta 69, 2221-2240. 
Blattmann, T. M., Wang, S. L., Lupker, M., Märki, L., Haghipour, N., Wacker, L., Chung, L.H., Bernasconi, S.M., Plötze, M., Eglinton, T.I., 2019. Sulphuric acid-mediated weathering on Taiwan buffers geological atmospheric carbon sinks. Sci. Rep. 9, 1-8.

Bouchez, J., Beyssac, O., Galy, V., Gaillardet, J., France-Lanord, C., Maurice, L., MoreiraTurcq, P., 2010. Oxidation of petrogenic organic carbon in the Amazon floodplain as a source of atmospheric $\mathrm{CO}_{2}$. Geology 38, 255-258.

Bouvier, A., Vervoort, J.D., Patchett, P.J., 2008. The Lu-Hf and Sm-Nd isotopic composition of CHUR: constraints from unequilibrated chondrites and implications for the bulk composition of terrestrial planets. Earth Planet. Sci. Lett. 273, 48-57.

Boyle, E.A., Edmond, J.M., Sholkovitz, E.R., 1977. The mechanism of iron removal in estuaries. Geochim. Cosmochim. Acta 41, 1313-1324.

Calmels, D., Gaillardet, J., Brenot, A., France-Lanord, C., 2007. Sustained sulphide oxidation by physical erosion processes in the Mackenzie River basin: climatic perspectives. Geology 35, 1003-1006.

Caves, J.K., Jost, A.B., Lau, K.V., Maher, K., 2016. Cenozoic carbon cycle imbalances and a variable silicate weathering feedback. Earth Planet. Sci. Lett. 450, 152-163.

Caves-Rugenstein, J.K., Ibarra, D.E., von Blanckenburg, F., 2019. Neogene cooling driven by land surface reactivity rather than increased weathering fluxes. Nature 571, 99-102.

Chen, J. B., Busigny, V., Gaillardet, J., Louvat, P., Wang, Y.N., 2014. Iron isotopes in the Seine River (France): Natural versus anthropogenic sources. Geochim. Cosmochim. Acta $128,128-143$.

Dausmann, V., Gutjahr, M., Frank, M., Kouzmanov, K., Schaltegger, U., 2019. Experimental evidence for mineral-controlled release of radiogenic $\mathrm{Nd}$, $\mathrm{Hf}$ and $\mathrm{Pb}$ isotopes from granitic rocks during progressive chemical weathering. Chem. Geol. 507, 64-84.

Drever, J.I., Zobrist, J., 1992. Chemical weathering of silicate rocks as a function of elevation 
in the southern Swiss Alps. Geochim. Cosmochim. Acta 56, 3209-3216.

Elderfield, H., Sholkovitz, E.T., 1987. Rare earth elements in the pore waters of reducing nearshore sediments. Earth Planet. Sci. Lett. 82, 280-288.

Elmore, A.C., Piotrowski, A.M., Wright, J.D., Scrivner, A.E., 2011. Testing the extraction of past seawater Nd isotopic composition from North Atlantic deep sea sediments and foraminifera. Geochem. Geophys. Geosyst. 12(9).

Franchi, F., Rovere, M., Gamberi, F., Rashed, H., Vaselli, O., Tassi, F., 2017. Authigenic minerals from the Paola Ridge (southern Tyrrhenian Sea): Evidences of episodic methane seepage. Mar. Petrol. Geol. 86, 228-247.

Gaillardet, J., Dupré, B., Louvat, P., Allègre, C.J., 1999. Global silicate weathering and $\mathrm{CO}_{2}$ consumption rates deduced from the chemistry of large rivers. Chem. Geol. 159, 3-30.

Gaillardet, J., Calmels, D., Romero-Mujalli, G., Zakharova, E., Hartmann, J., 2019. Global climate control on carbonate weathering intensity. Chem. Geol. 118762.

Goldstein, S.J., Jacobsen, S.B., 1987. The Nd and Sr isotopic systematics of river-water dissolved material: Implications for the sources of $\mathrm{Nd}$ and $\mathrm{Sr}$ in seawater. Chem. Geol. $46,245-272$.

Gutjahr, M., Frank, M., Stirling, C.H., Klemm, V., Van de Flierdt, T., Halliday, A.N., 2007. Reliable extraction of a deepwater trace metal isotope signal from $\mathrm{Fe}-\mathrm{Mn}$ oxyhydroxide coatings of marine sediments. Chem. Geol. 242, 351-370.

Haley, B.A., Klinkhammer, G.P., McManus, J., 2004. Rare earth elements in pore waters of marine sediments. Geochim. Cosmochim. Acta 68, 1265-1279.

Haley, B.A., Du, J., Abbott, A.N., McManus, J., 2017. The impact of benthic processes on rare earth element and neodymium isotope distributions in the oceans. Front. Mar. Sci. 4, 426.

Hartmann, J., Moosdorf, N., 2012. The new global lithological map database GLiM: A 
representation of rock properties at the Earth surface. Geochem. Geophys. Geosyst. 13.

Hartmann, J., Moosdorf, N., Lauerwald, R., Hinderer, M., West, A.J., 2014. Global chemical weathering and associated P-release-The role of lithology, temperature and soil properties. Chem. Geol. 363, 145-163.

Himmler, T., Haley, B.A., Torres, M.E., Klinkhammer, G.P., Bohrmann, G., Peckmann, J., 2013. Rare earth element geochemistry in cold-seep pore waters of Hydrate Ridge, northeast Pacific Ocean. Geo-Mar. Lett. 33, 369-379.

Hindshaw, R.S., Aciego, S.M., Piotrowski, A.M., Tipper, E.T., 2018. Decoupling of dissolved and bedrock neodymium isotopes during sedimentary cycling. Geochem. Persp. Let. 8, 43-46.

Horan, K., Hilton, R.G., Selby, D., Ottley, C.J., Gröcke, D.R., Hicks, M., Burton, K.W., 2017. Mountain glaciation drives rapid oxidation of rock-bound organic carbon. Sci. Adv. 3, e1701107.

Jacobson, A.D., Blum, J.D., Walter, L.M., 2002. Reconciling the elemental and Sr isotope composition of Himalayan weathering fluxes: insights from the carbonate geochemistry of stream waters. Geochim. Cosmochim. Acta 66, 3417-3429.

Jacobson, A.D., Blum, J.D., 2003. Relationship between mechanical erosion and atmospheric CO2 consumption in the New Zealand Southern Alps. Geology 31, 865-868.

Jacobson, A.D., Blum, J.D., Chamberlain, C.P., Craw, D., Koons, P.O., 2003. Climatic and tectonic controls on chemical weathering in the New Zealand Southern Alps. Geochim. Cosmochim. Acta 67, 29-46.

Jang, K., Bayon, G., Han, Y., Joo, Y.J., Kim, J.H., Ryu, J.S., Woo, J., Forwick, M., Szczuciński, W., Kim, J.H., Nam, S.I., 2020. Neodymium isotope constraints on chemical weathering and past glacial activity in Svalbard. Earth Planet. Sci. Lett. 542, 116319.

Jochum, K.P., Nohl, U., Herwig, K., Lammel, E., Stoll, B., Hofmann, A.W., 2005. GeoReM: 
a new geochemical database for reference materials and isotopic standards. Geostand. Geoanal. Res. 29, 333-338.

Johannesson, K.H., Burdige, D.J., 2007. Balancing the global oceanic neodymium budget: evaluating the role of groundwater. Earth Planet. Sci. Lett. 253, 129-142.

Lacan, F., Tachikawa, K., Jeandel, C., 2012. Neodymium isotopic composition of the oceans: A compilation of seawater data. Chem. Geol. 300, 177-184.

Lara, R.H., Monroy, M.G., Mallet, M., Dossot, M., González, M.A., Cruz, R., 2015. An experimental study of iron sulfides weathering under simulated calcareous soil conditions. Environ. Earth Sci. 73, 1849-1869.

Lawrence, M. G., Greig, A., Collerson, K.D., Kamber, B.S., 2006. Rare earth element and yttrium variability in South East Queensland waterways. Aquat. Geochem. 12, 39-72.

Lehner, B., Grill, G., 2013. Global river hydrography and network routing: baseline data and new approaches to study the world's large river systems. Hydrol. Process. 27, 21712186.

Li, G., Elderfield, H., 2013. Evolution of carbon cycle over past 100 million years. Geochim. Cosmochim. Acta 103, 11-25.

Li, G., Hartmann, J., Derry, L.A., West, A.J., You, C.F., Long, X., Zhan, T., Li, L., Li, G., Qiu, W., Li, T., 2016. Temperature dependence of basalt weathering. Earth Planet. Sci. Lett. 443, 59-69.

Martin, E.E., Blair, S.W., Kamenov, G.D., Scher, H.D., Bourbon, E., Basak, C., Newkirk, D. N., 2010. Extraction of Nd isotopes from bulk deep sea sediments for paleoceanographic studies on Cenozoic time scales. Chem. Geol. 269, 414-431.

Meyer, H.W., 1992. Lapse rates and other variables applied to estimating paleoaltitudes from fossil floras. Palaeogeog. Palaeoclimatol. Palaeoecol. 99, 71-99.

Milliman, J.D., Farnsworth, K.L., 2011. River Discharge to the Coastal Ocean, A global 
synthesis. Cambridge University Press, 392 pp.

Molina-Kescher, M., Frank, M., Hathorne, E.C., 2014. Nd and Sr isotope compositions of different phases of surface sediments in the South Pacific: Extraction of seawater signatures, boundary exchange, and detrital/dust provenance. Geochem. Geophys. Geosyst. 15, 3502-3520.

Moore, J., Jacobson, A.D., Holmden, C., Craw, D., 2013. Tracking the relationship between mountain uplift, silicate weathering, and long-term $\mathrm{CO} 2$ consumption with $\mathrm{Ca}$ isotopes: Southern Alps, New Zealand. Chem. Geol. 341, 110-127.

Porcelli, D., Andersson, P.S., Baskaran, M., Frank, M., Björk, G., Semiletov, I., 2009. The distribution of neodymium isotopes in Arctic Ocean basins. Geochim. Cosmochim. Acta, $73,2645-2659$.

Poulton, S.W., Canfield, D.E., 2005. Development of a sequential extraction procedure for iron: implications for iron partitioning in continentally derived particulates. Chem. Geol. 214, 209-221.

Raymo, M.E., Ruddiman, W.F., 1992. Tectonic forcing of late Cenozoic climate. Nature 359, 117-122.

Riebe, C.S., Kirchner, J.W., Granger, D.E., Finkel, R.C., 2001. Strong tectonic and weak climatic control of long-term chemical weathering rates. Geology 29, 511-514.

Rongemaille, E., Bayon, G., Pierre, C., Bollinger, C., Chu, N.C., Fouquet, Y., Riboulot, V., Voisset, M., 2011. Rare earth elements in cold seep carbonates from the Niger delta. Chem. Geol. 286, 196-206.

Rousseau, T.C., Sonke, J. E., Chmeleff, J., Van Beek, P., Souhaut, M., Boaventura, G., Seyler, P., Jeandel, C., 2015. Rapid neodymium release to marine waters from lithogenic sediments in the Amazon estuary. Nature Commun. 6, 7592.

Scrivner, A.E., Vance, D., Rohling, E.J., 2004. New neodymium isotope data quantify Nile 
involvement in Mediterranean anoxic episodes. Geology 32, 565-568.

Sholkovitz, E.R., Piepgras, D.J., Jacobsen, S.B., 1989. The pore water chemistry of rare earth elements in Buzzards Bay sediments. Geochim. Cosmochim. Acta 53, 2847-2856.

Sholkovitz, E.R., Shaw, T.J., Schneider, D.L., 1992. The geochemistry of rare earth elements in the seasonally anoxic water column and porewaters of Chesapeake Bay. Geochim. Cosmochim. Acta 56, 3389-3402.

Sholkovitz, E., Szymczak, R., 2000. The estuarine chemistry of rare earth elements: comparison of the Amazon, Fly, Sepik and the Gulf of Papua systems. Earth Planet. Sci. Lett. 179, 299-309.

Spence, J., Telmer, K., 2005. The role of sulfur in chemical weathering and atmospheric $\mathrm{CO}_{2}$ fluxes: evidence from major ions, $\delta 13 \mathrm{C}_{\mathrm{DIC}}$, and $\delta 34 \mathrm{~S}_{\mathrm{SO} 4}$ in rivers of the Canadian Cordillera. Geochim. Cosmochim. Acta 69, 5441-5458.

Stallard, R.F., Edmond, J.M., 1983. Geochemistry of the Amazon: 2. The influence of geology and weathering environment on the dissolved load. J. Geophys. Res. Oceans 88, 9671-9688.

Süfke, F., Gutjahr, M., Gilli, A., Anselmetti, F.S., Glur, L., Eisenhauer, A., 2019. Early stage weathering systematics of $\mathrm{Pb}$ and $\mathrm{Nd}$ isotopes derived from a high-Alpine Holocene lake sediment record. Chem. Geol. 507, 42-53.

Tachikawa, K., Roy-Barman, M., Michard, A., Thouron, D., Yeghicheyan, D., Jeandel, C., 2004. Neodymium isotopes in the Mediterranean Sea: comparison between seawater and sediment signals. Geochim. Cosmochim. Acta 68, 3095-3106.

Torres, M.A., West, A.J., Li, G., 2014. Sulphide oxidation and carbonate dissolution as a source of $\mathrm{CO}_{2}$ over geological timescales. Nature 507, 346-349.

Torres, M.A. et al., 2016. The acid and alkalinity budgets of weathering in the AndesAmazon system: Insights into the erosional control of global biogeochemical cycles. 
Earth Planet. Sci. Lett. 450, 381-391.

Torres, M.A., Moosdorf, N., Hartmann, J., Adkins, J.F., West, A.J., 2017. Glacial weathering, sulphide oxidation, and global carbon cycle feedbacks. Proc. Nat. Acad. Sci. U.S.A. 114, 8716-8721.

Tostevin, R., Shields, G.A., Tarbuck, G.M., He, T., Clarkson, M.O., Wood, R.A., 2016. Effective use of cerium anomalies as a redox proxy in carbonate-dominated marine settings. Chem. Geol. 438, 146-162.

Velbel, M.A., 1993. Temperature dependence of silicate weathering in nature: How strong a negative feedback on long-term accumulation of atmospheric $\mathrm{CO} 2$ and global greenhouse warming? Geology 21, 1059-1062.

von Blanckenburg, F., Bouchez, J., Ibarra, D.E., Maher, K., 2015. Stable runoff and weathering fluxes into the oceans over Quaternary climate cycles. Nat. Geosci. 8, 538542.

Walker, J.C.G., Hays, P.B., Kasting, J.F.A, 1981. negative feedback mechanism for the longterm stabilization of Earth's surface temperature. J. Geophys. Res. 86, 9776-9782.

West, A. J., Galy, A., Bickle, M., 2005. Tectonic and climatic controls on silicate weathering. Earth Planet. Sci. Lett. 235, 211-228.

West, A.J., 2012. Thickness of the chemical weathering zone and implications for erosional and climatic drivers of weathering and for carbon-cycle feedbacks. Geology 40, 811-814.

White, A.F., Blum, A.E., Bullen, T.D., Vivit, D.V., Schulz, M., Fitzpatrick, J., 1999. The effect of temperature on experimental and natural chemical weathering rates of granitoid rocks. Geochim. Cosmochim. Acta 63, 3277-3291.

Willenbring, J.K., von Blanckenburg, F., 2010. Long-term stability of global erosion rates and weathering during late-Cenozoic cooling. Nature 465, 211-214.

Wilson, D.J., Piotrowski, A.M., Galy, A., Clegg, J.A., 2013. Reactivity of neodymium 
carriers in deep sea sediments: Implications for boundary exchange and paleoceanography. Geochim. Cosmochim. Acta 109, 197-221.

Yu, Z., Colin, C., Bassinot, F., Wan, S., Bayon, G., 2020. Climate-driven weathering shifts between highlands and floodplains. Geochem. Geophys. Geosyst., e2020GC008936.

\section{Figure captions}

Figure 1. The location of studied sediment samples and corresponding river basins. Yellow and green diamonds correspond to rivers from cratonic areas (associated with igneous/metamorphic crystalline basements rocks) and volcanic watersheds, respectively. Black circles indicate rivers draining coastal plains, lowlands and uplands; and white triangles, those flowing from mountain environments with an elevation higher than 1000 meters above sea-level. Note that the numbers corresponds to the samples listed in Table 1. The digital elevation model is derived from the ETOPO1 Global relief Model (https://www.ngdc.noaa.gov/mgg/global/global.html). Digital hydrographic information for rivers and watersheds is derived from HydroBASINS (http://www.hydrosheds.org/page/overview; Lehner and Grill, 2013).

Figure 2. Shale-normalized (WRAS; Bayon et al., 2015) REE patterns for riverine Fe oxides from (a) igneous and metamorphic crystalline basements; (b) volcanic provinces; (c) lowelevation regions $(<1000 \mathrm{~m})$ draining sedimentary and multi-lithological catchments regions; and (d) mountainous regions (> 1000m) draining sedimentary and multilithological catchments. For clarity, note that the REE data for leached sediment fractions (reported relative to the initial mass of bulk sediment) were also normalized Gd wRAs. The thin grey lines correspond to individual samples, while the thicker line with symbols represent the average shale-normalized pattern for each sample category. Also reported 
are the concavity indices (CI) for each category of rivers, calculated using the weighted geometric means of shale-normalized $\mathrm{La}$ and $\mathrm{Yb}$ (see text for details).

Figure 3. The distribution of $\mathrm{Nd}$ isotopes in paired Fe-oxide and silicate detrital fractions of world river sediments. In (a) the dotted line corresponds to a 1:1 relationship between $\mathrm{Nd}$ isotopes (expressed using the epsilon notation $\varepsilon_{\mathrm{Nd}}$ ) in Fe-oxide and detrital fractions. In (b) $\Delta \varepsilon_{\mathrm{Nd}}$ Feox-Det represents the $\mathrm{Nd}$ isotopic difference measured between paired $\mathrm{Fe}$ oxide and detrital silicate fractions. River sediments from crystalline basements (yellow diamonds) and volcanic watersheds (green diamonds) display near zero $\Delta \varepsilon_{\mathrm{Nd}}$ FeoxDet values (mean $0.5 \pm 1.1$ ), indicating that Fe-oxides are mostly derived from alteration of silicate rocks. The other studied sediment samples (black circles: coastal plains and lowlands; white triangles: mountains) come from watersheds hosting mixed lithologies, and are systematically shifted towards positive $\Delta \varepsilon_{\mathrm{Nd}}$ Feox-Det values, which we interpret here as mainly reflecting the signature of ancient Fe oxides of marine origin derived from the alteration and/or erosion of sedimentary rocks.

Figure 4. Relationship between $\mathrm{Sr} / \mathrm{Ca}$ and $\mathrm{Mg} / \mathrm{Ca}$ ratios in leached (Fe-oxide bearing) sediment fractions. The endmember mixing model is adapted from Bayon et al. (2007), using the following endmember compositions: aragonite (Sr: 10,500 ppm; Mg: 180 ppm; Ca: 39\%; Bayon et al., 2007), low-Mg calcite (Sr: 1,200 ppm; Mg: 250 ppm; Ca: 42.2\%; Bayon et al., 2007), detrital silicate (Sr: 127 ppm; Mg: 9,980 ppm; Ca: 6,735 ppm; WRAS values; Bayon et al., 2015) and dolomite (Sr: 100 ppm; Mg: 11.5\%; Ca: 22.5\%; compilation of literature data). The blue dots on mixing lines correspond to $20 \%$ contribution increments from each two endmembers. The symbols for leached sediment fractions correspond to river sediments from igneous/metamorphic terranes (yellow 
diamonds), volcanic watersheds (green diamonds), low- (black circles) and high-(red triangles) elevation sedimentary catchments. The black crosses correspond to corresponding silt-size silicate fractions.

Figure 5. Relationships between (a) $\mathrm{Sr} / \mathrm{Ca}$ and $\mathrm{Fe} / \mathrm{Mg}$ and (b) $\mathrm{Sr} / \mathrm{Ca}$ and $\mathrm{Fe} / \mathrm{Al}$ in leached sediment fractions. For symbols; see the caption of Fig. 6. The blue squares correspond to potential end-members for detrital sediments (WRAS; Bayon et al., 2015) and dolomite (compilation of literature data). The departure of leached sediment fractions from the above endmember $\mathrm{Fe} / \mathrm{Mg}$ and $\mathrm{Fe} / \mathrm{Al}$ compositions indicates that $\mathrm{Fe}$ in these samples is mostly associated with Fe-oxide mineral phases. The blue fields correspond to the observed range of elemental ratios for various certified reference materials corresponding to terrestrial iron formations (FeR-1, Fe-R2, FeR-4, IF-G) and marine Fe-rich precipitates (OOPE601, OOPE603, NOD-A-1, GSPN-1, GL-O) [data derived from the GEOREM web portal; Jochum et al., 2005].

Figure 6. Shale-normalized $(\mathrm{Gd} / \mathrm{Yb})_{\mathrm{N}}$ versus $(\mathrm{La} / \mathrm{Gd})_{\mathrm{N}}$ plot in (a) pore waters, seawater and detrital fractions of river sediments; and (b) marine Fe-oxyhydroxide phases. The dashed lines correspond to theoretical values of the concavity index (CI) of corresponding shalenormalized REE patterns, calculated geometrically from La and $\mathrm{Yb}$ on a log-linear REE pattern using the following equation $(\mathrm{La} / \mathrm{Gd})_{\mathrm{N}}=\left[(\mathrm{Gd} / \mathrm{Yb})_{\mathrm{N}} \times 1 / x\right]^{7 / 6} / x$; where $x$ represents theoretical CI values. Data for sub-seafloor pore waters (Elderfield and Sholkovitz, 1987; Sholkovitz et al., 1989; Sholkovitz et al., 1992; Haley et al., 2004; Bayon et al., 2011; Himmler et al., 2013; Abbott et al., 2015), detrital river sediments (Bayon et al., 2015), diagenetic and hydrogenous Fe-Mn deposits (Bau et al., 2014) and leached Fe-oxyhydroxide phases from marine sediments (Bayon et al., 2004; Martin et 
al., 2010; Basak et al., 2011; Wilson et al., 2013; Molina-Kescher et al., 2014; Casse et al., 2019) are shown for comparison. The references used for seawater values are listed in Table S4. The coloured field in panel (b) represents the range of sub-seafloor pore water data. Note that the colour gradient from yellow to blue indicates changing pore water REE compositions from oxic to suboxic conditions, respectively (e.g. Haley et al., 2004; Abbott et al., 2015).

Figure 7. Using the concavity index $(\mathrm{CI})$ and $\mathrm{Nd}$ isotopes for discriminating the source of $\mathrm{Fe}$ oxides in sediments. (a) Shale-normalized $(\mathrm{Gd} / \mathrm{Yb})_{\mathrm{N}}$ versus $(\mathrm{La} / \mathrm{Gd})_{\mathrm{N}}$ plot in leached $\mathrm{Fe}$ oxide fractions of river sediments. The dashed lines correspond to theoretical values of the concavity index (CI) of corresponding shale-normalized REE patterns, which enable to distinguish between several types of Fe-oxides in sediments: marine Fe-oxyhydroxide phases, volcanogenic Fe-oxides, secondary Fe-oxides (formed via alteration of silicate rocks), secondary Fe-oxides (formed presumably via oxidative weathering of sedimentary sulphide minerals), ancient marine Fe oxides derived from the alteration and/or erosion of sedimentary rocks. The coloured field in represents the range of marine Fe-oxyhydroxide phases inferred from pore water data. Note that the colour gradient from yellow to blue indicates changing pore water REE compositions between hydrogenous and diagenetic Fe-oxides formed under oxic and suboxic conditions, respectively. (b) REE concavity index (CI) versus $\Delta \varepsilon_{\mathrm{Nd}}$ Feox-Det in leached Fe oxide fractions. The broad correlation between $\mathrm{CI}$ and $\Delta \varepsilon_{\mathrm{Nd}}$ Feox-Det indicates that the Nd isotope decoupling in paired Fe-oxide and detrital fractions in river sediments is mostly controlled by the relative contribution of secondary $\mathrm{Fe}$ oxides derived from the alteration of crystalline silicate rocks (when $\Delta \varepsilon_{\mathrm{Nd}}$ Feox-Det $<1.6$ and CI values $<2$ ) and ancient marine Fe oxides derived from the erosion and/or alteration of sedimentary rocks in watersheds (when $\Delta \varepsilon_{\mathrm{Nd} \text { Feox-Det }}>1.6$ and 
CI values $>2$ ).

Figure 8. Comparison of $\Delta \varepsilon_{\mathrm{Nd}}$ Feox-Det with carbonate-silicate weathering indices in major world river basins. The estimates for carbonate-silicate weathering rates reported here for comparison were calculated by inverse modelling of river chemistry data (Gaillardet et al., 1999). (a) $\Delta \varepsilon_{\mathrm{Nd}}$ Feox-Det versus percentage relative contribution of carbonate weathering to total weathering rates. (b) $\Delta \varepsilon_{\mathrm{Nd}}$ Feox-Det versus carbonate-silicate weathering ratio (logarithmic scale). The observed general relationships suggest that $\Delta \varepsilon_{\mathrm{Nd}}$ Feox-Det $\mathrm{can}$ be used as a proxy for estimating the relative contribution of sedimentary (carbonate-rich) versus crystalline silicate rock weathering in modern and past environments. The symbols with dotted contours correspond those samples that depart from the observed relationships due to preferential alteration of basaltic rocks (Paraná and Fraser) or anthropogenic influence (Seine, Rhine, Yangtze).

Figure 9. Relationships between $\Delta \varepsilon_{\mathrm{Nd}}$ Feox-Det and (a) mean annual temperature (MAT), (b) maximum basin elevation and (c) percentage contributions of carbonate and mixed sedimentary rocks in low-elevation river basins (with maximum elevation $<1000 \mathrm{~m}$ ). The observed exponential correlation between $\Delta \varepsilon_{\mathrm{Nd}}$ Feox-Det and MAT indicate that temperature controls the relative contribution of sedimentary versus crystalline silicate rock weathering in low-elevation watersheds. The dotted circles in the panel (a) corresponds to samples that were excluded in the regression analysis, due to potential anthropogenic contamination (Seine) or dissolution of volcanogenic particles in watersheds hosting substantial basaltic outcrops (Lower River Bann: 34\%; Moyola: 32\%).

Figure 10. Relationships between $\Delta \varepsilon_{\mathrm{Nd}}$ Feox-Det and (a) mean annual temperature, (b) 
maximum basin elevation and (c) percentage contributions of carbonaceous sedimentary rocks in high-elevation river basins (with maximum elevation $>1000 \mathrm{~m}$ ). The observed correlation between $\Delta \varepsilon_{\mathrm{Nd}}$ Feox-Det and maximum basin elevation reflects a gradual shift from carbonate-dominated to silicate-dominated weathering regimes from high mountain environments to lowlands. The dotted triangles in the panel (a) correspond to those samples that were excluded from the regression analysis due to potential anthropogenic contamination (Yangtze, Rhine), dissolution of volcanogenic particles in catchments draining large areas of volcanic rocks (Fraser: 40\%; Chubut: 31\%; Sefid Rud: 29\%; Paraná: 14\%), dissolution of silicate detritus (Mekong) or due to the inferred presence of high amounts of carbonates in corresponding leachates (Nile, Danube, Nelson). Note that both exponential and linear best fit lines return similar coefficients of correlation $\left(\mathrm{R}^{2}=\right.$ 0.75 and 0.72 , respectively). However, the presumed temperature-dependency of this relationship suggests that exponential regression analysis may be more appropriate here. 
Table 1. Nd isotope and REE compositions of riverine Fe-oxide fractions and corresponding basin parameters

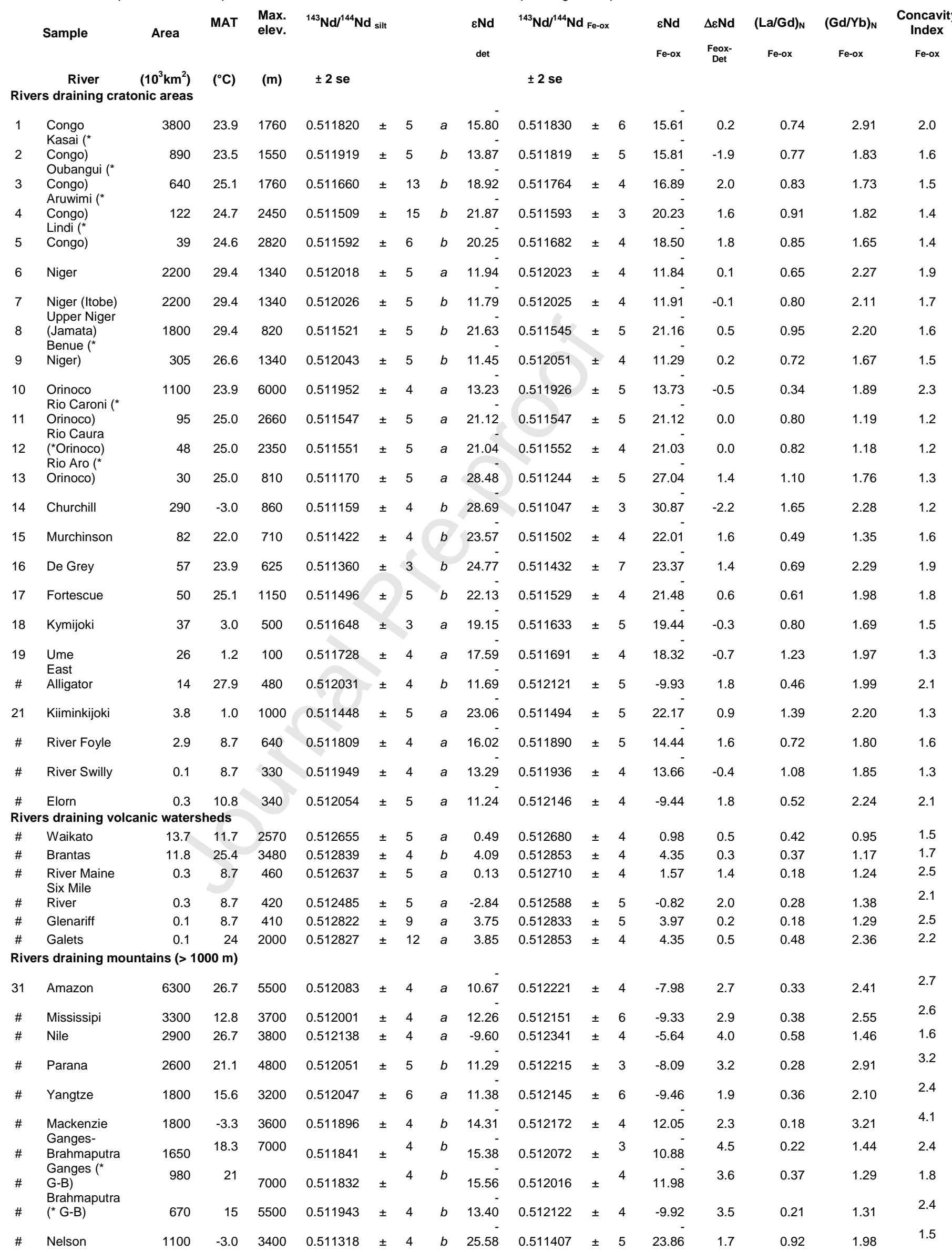




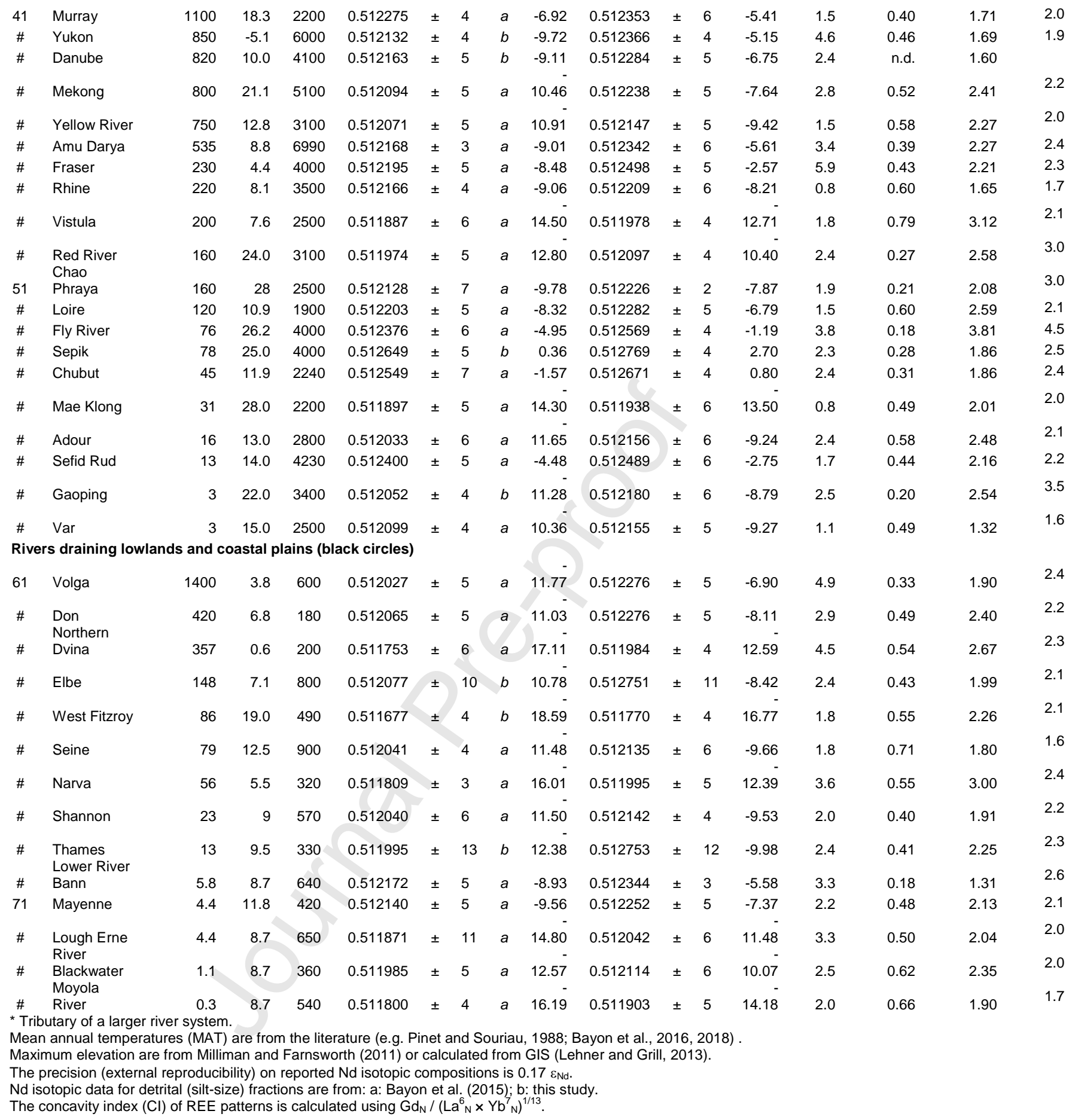


Declaration of competing interest

The authors declare that they have no known competing financial interests or personal relationships that could have appeared to influence the work reported in this paper. 


\section{Highlights}

World survey of REE and Nd isotopes in riverine Fe-oxides and detrital sediments A new REE index (concavity index) is defined to determine the types of iron oxides $\Delta \varepsilon_{\text {Nd Feox-Det }}$ as a new proxy for sedimentary versus crystalline rock weathering $\Delta \varepsilon_{\mathrm{Nd}}$ Feox-Det correlates with temperature and maximum elevation in watersheds Shift from silicate- to carbonate-weathering regime from lowlands to mountains 


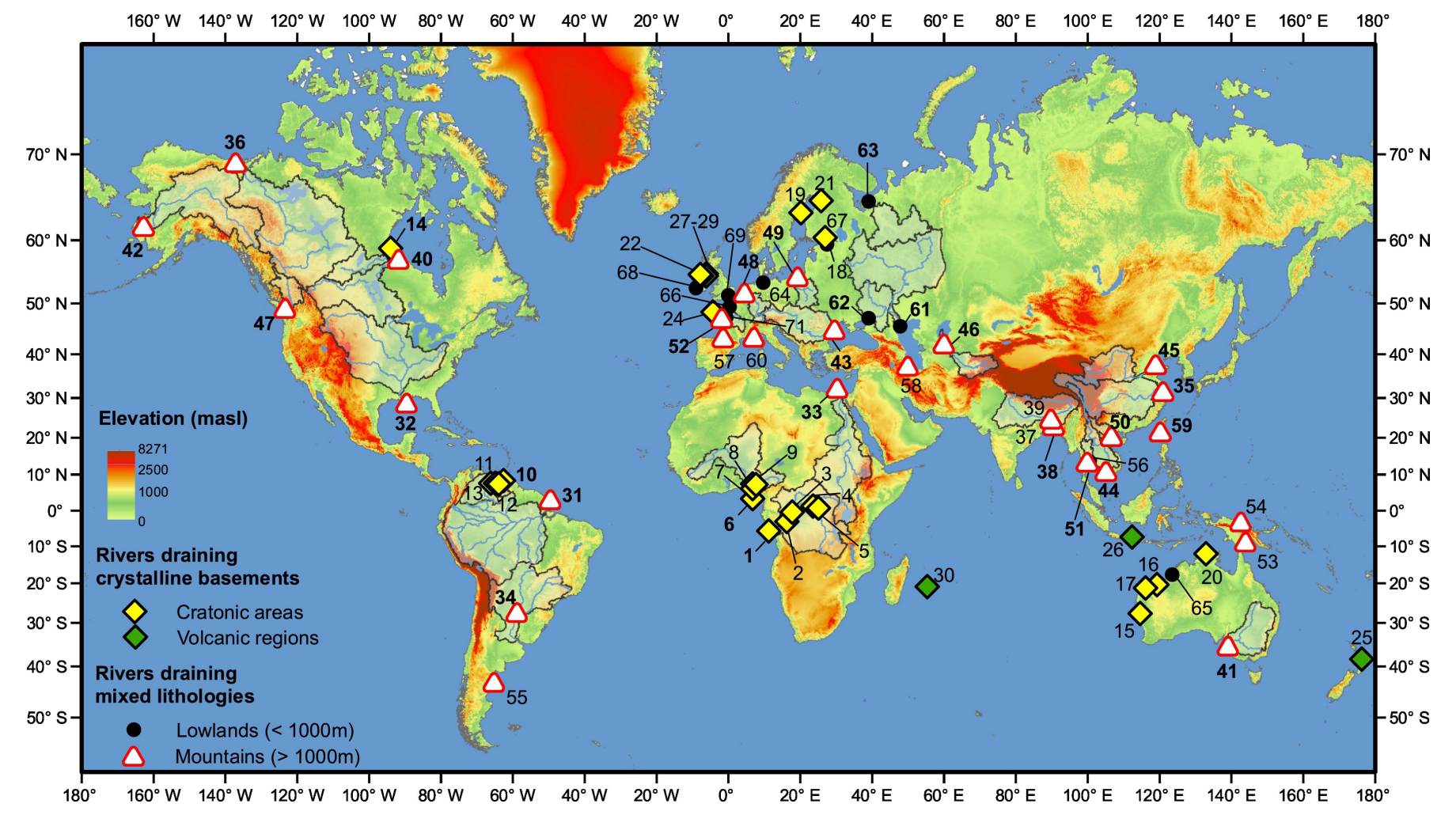

Figure 1 


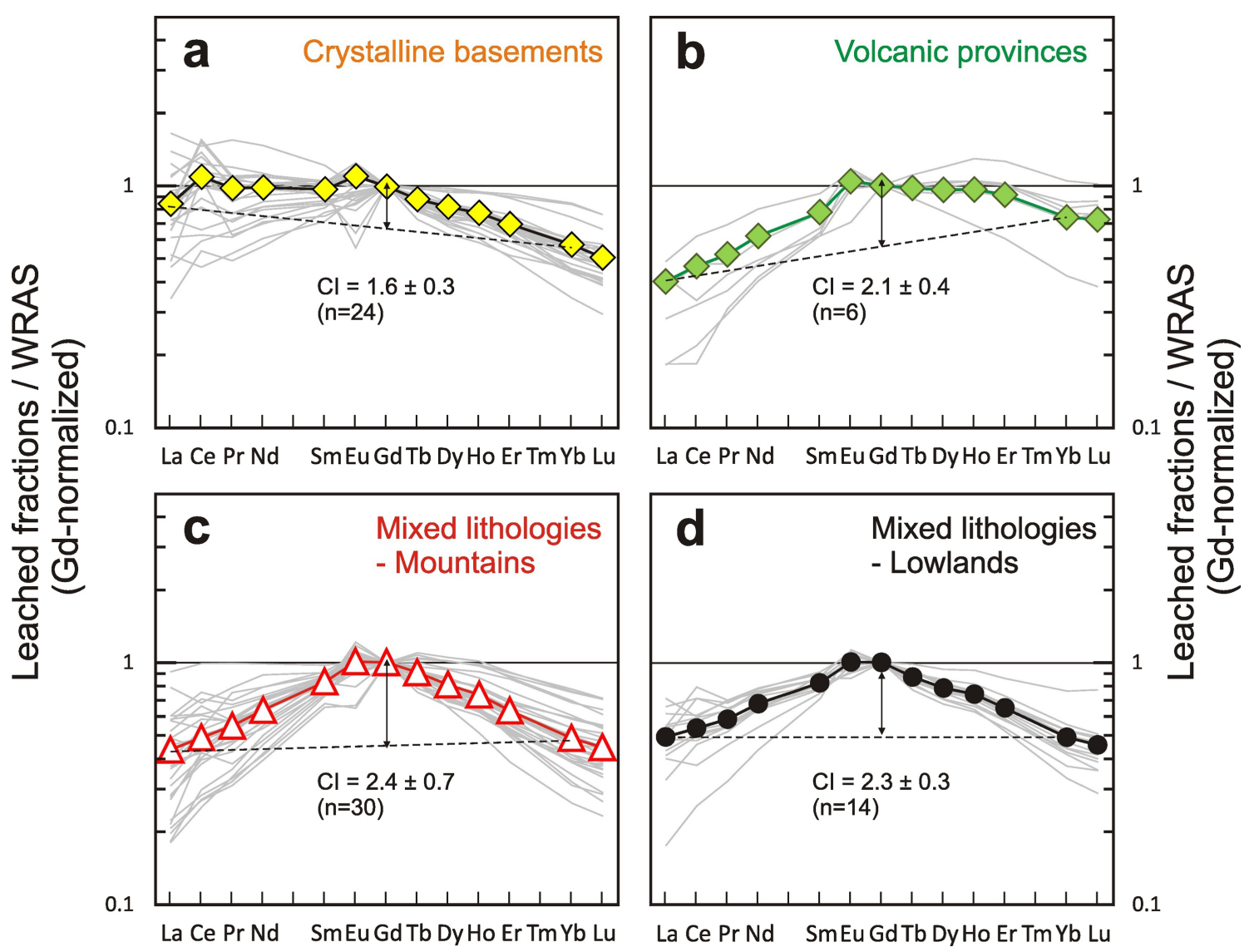



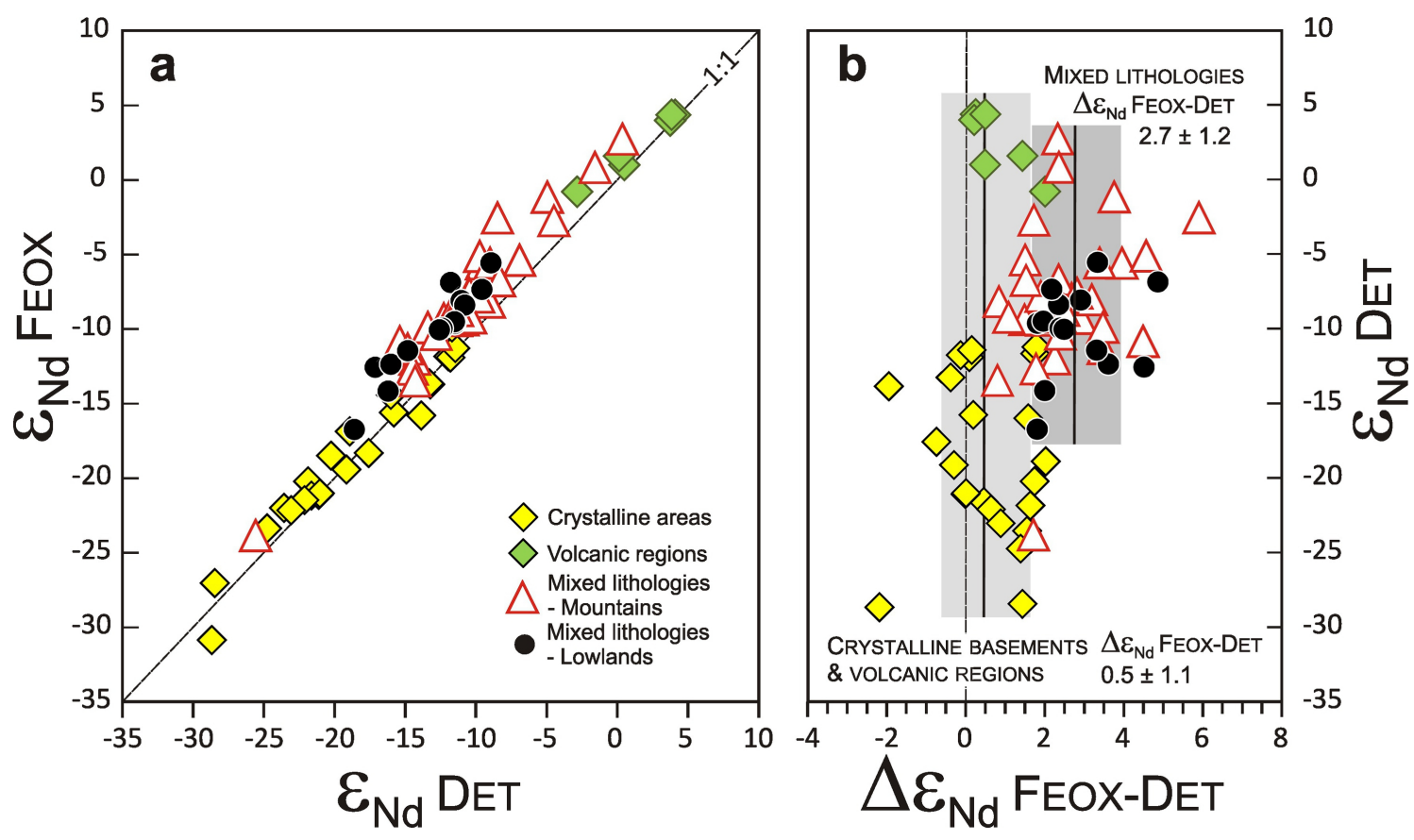

Figure 3 


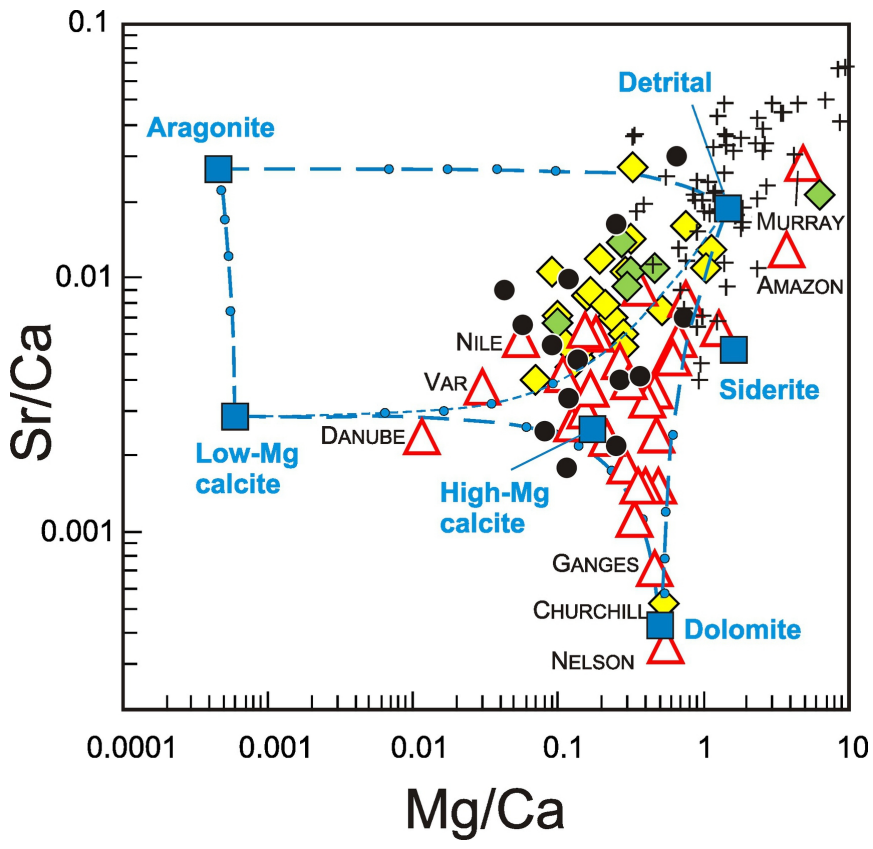

Figure 4 


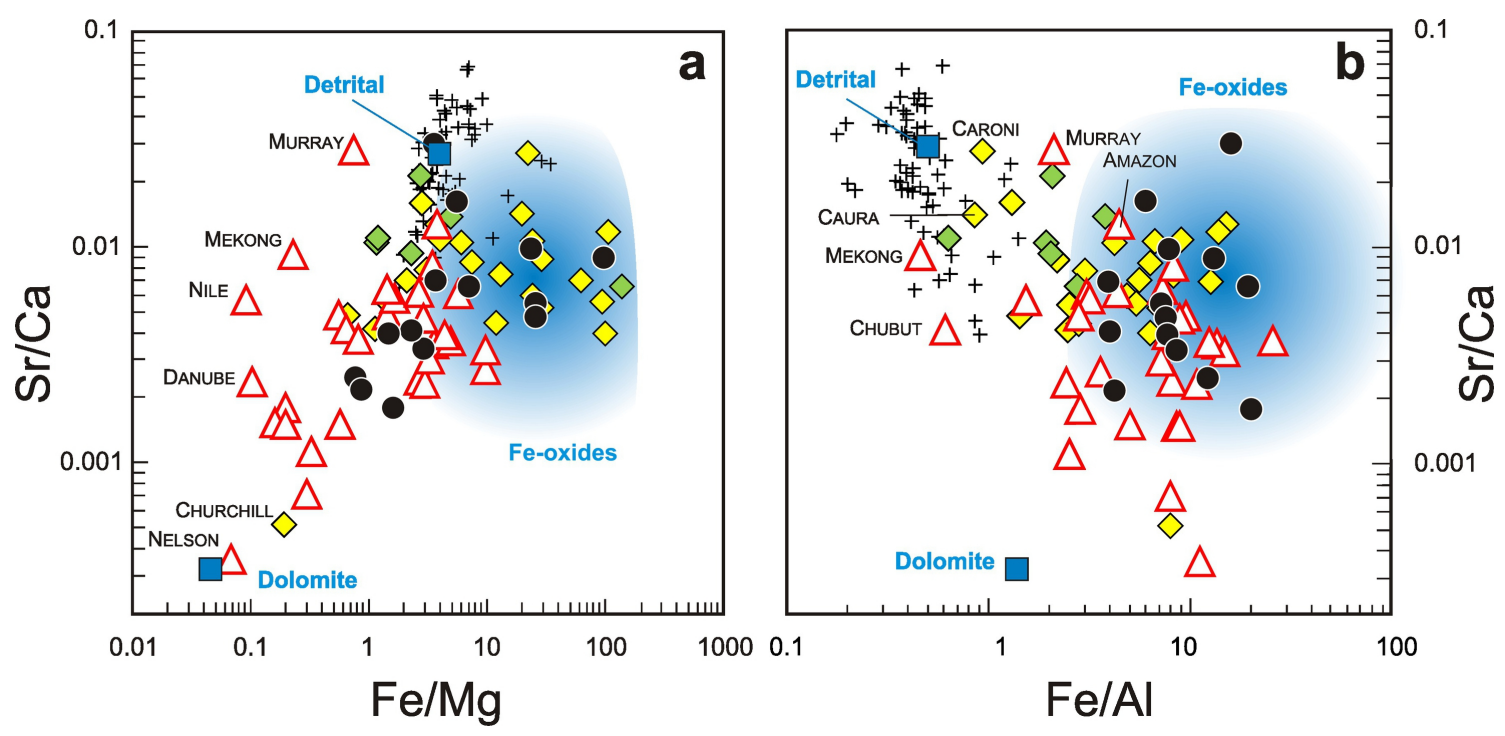

Figure 5 

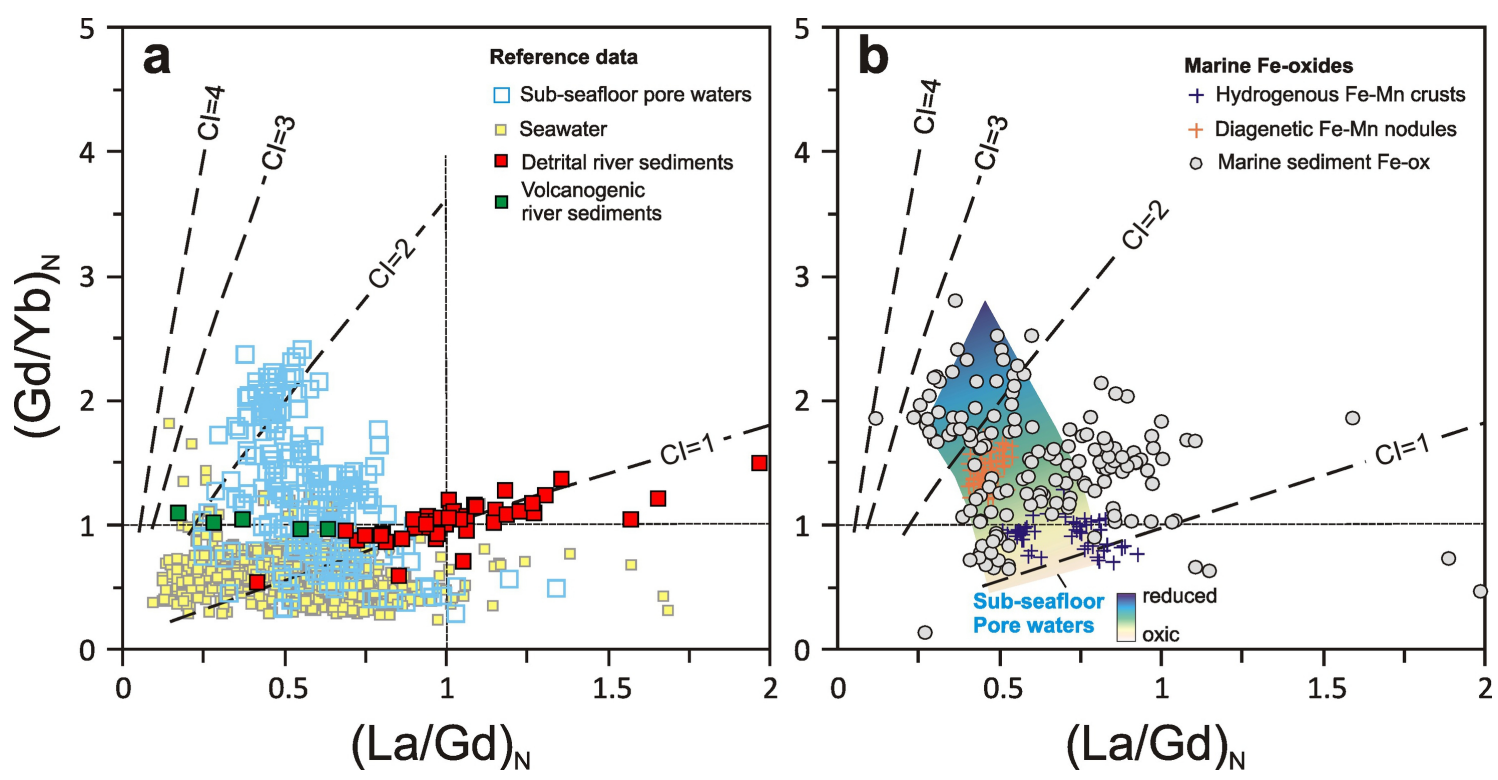

Figure 6 

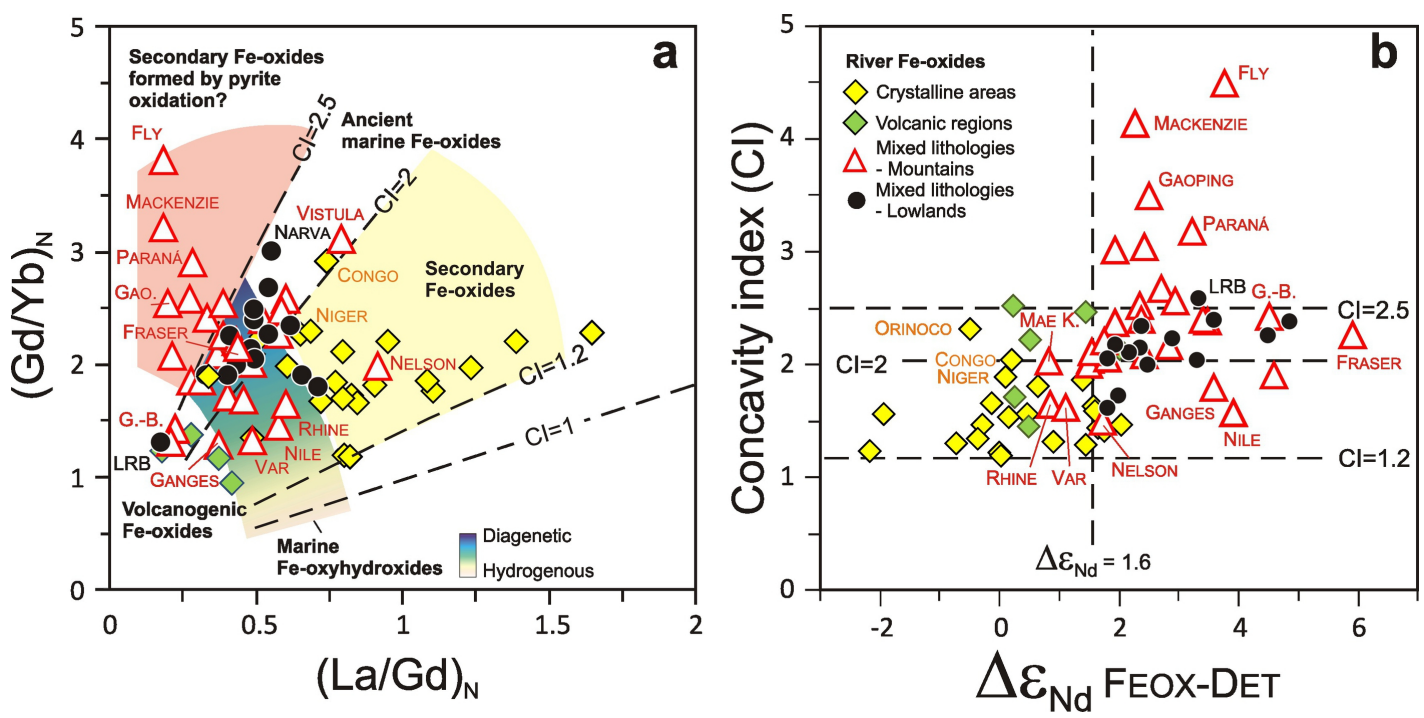

Figure 7 


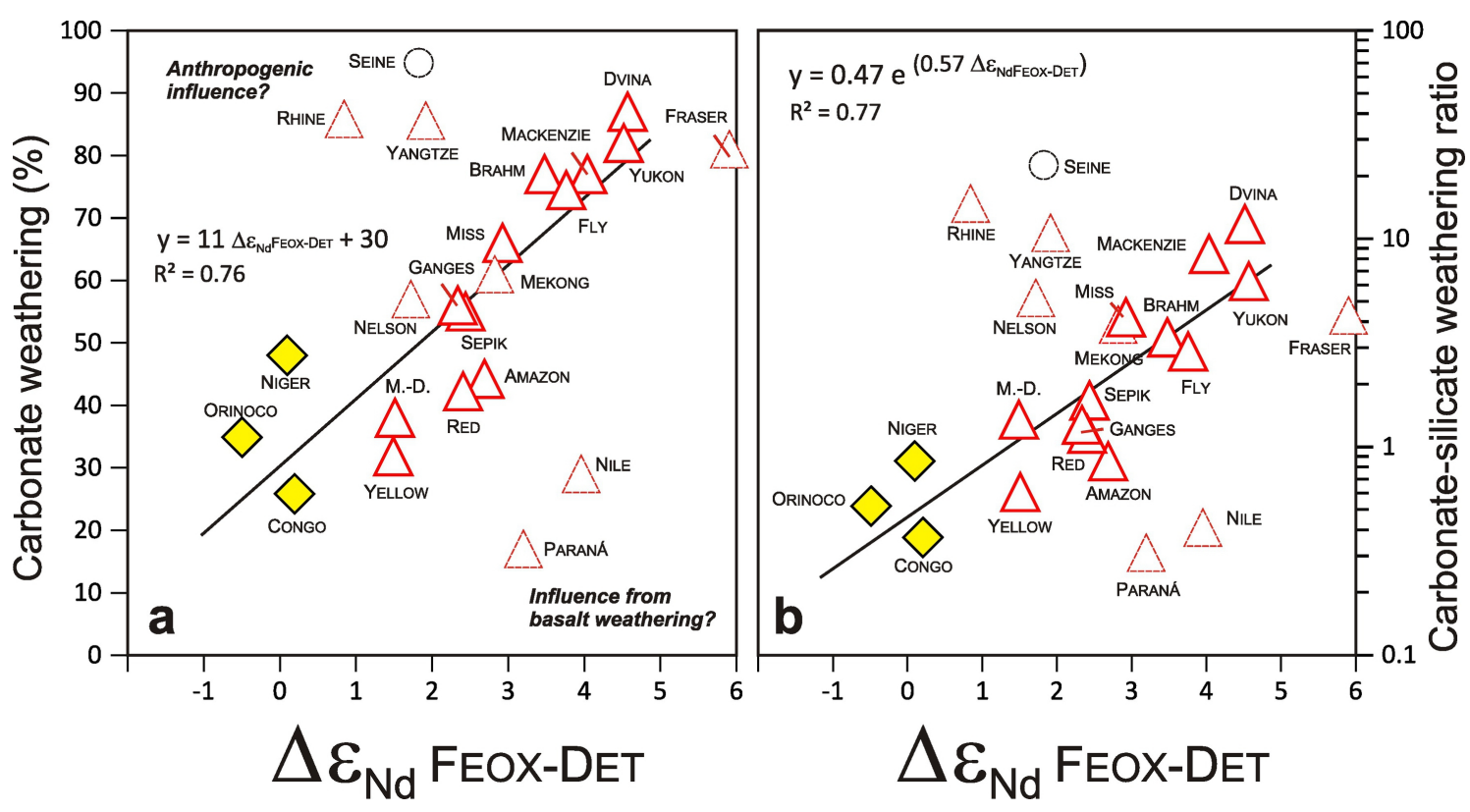

Figure 8 


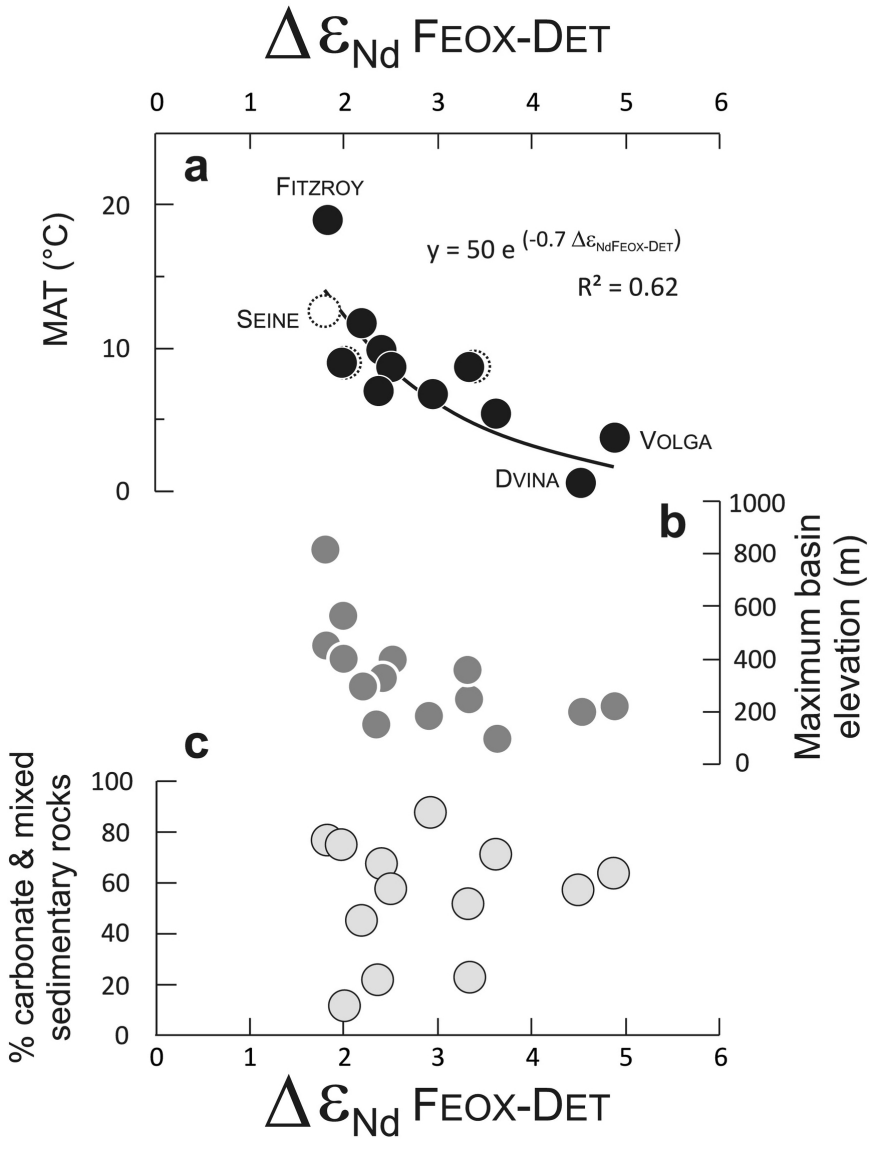

Figure 9 


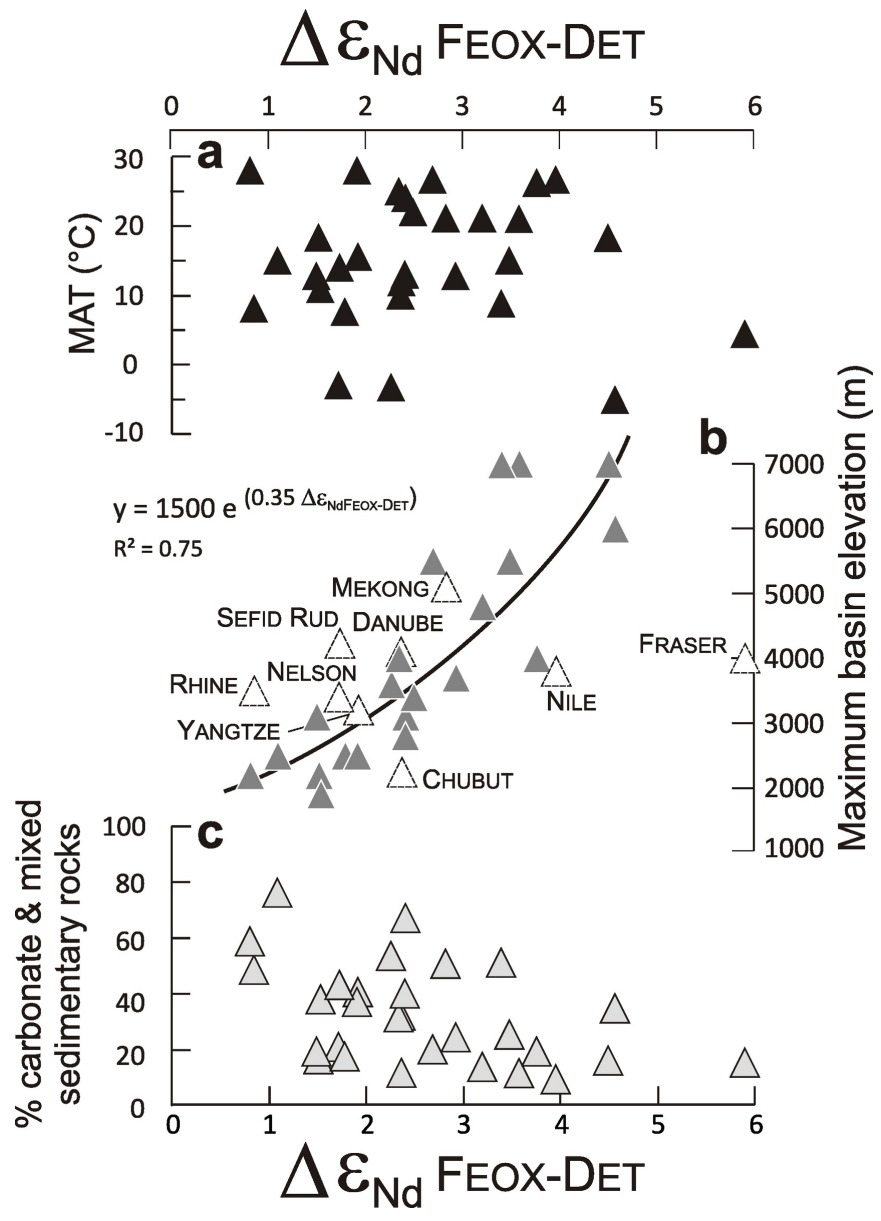

Figure 10 